\title{
Trends and applications of resilience analytics in supply chain modeling: systematic literature review in the context of the COVID-19 pandemic
}

\author{
Maureen S. Golan ${ }^{1} \cdot$ Laura H. Jernegan ${ }^{1} \cdot$ Igor Linkov $^{2} \mathbb{D}$ \\ Published online: 30 May 2020 \\ (c) This is a U.S. Government work and not under copyright protection in the US; foreign copyright protection may apply 2020
}

\begin{abstract}
The increasingly global context in which businesses operate supports innovation, but also increases uncertainty around supply chain disruptions. The COVID-19 pandemic clearly shows the lack of resilience in supply chains and the impact that disruptions may have on a global network scale as individual supply chain connections and nodes fail. This cascading failure underscores the need for the network analysis and advanced resilience analytics we find lacking in the existing supply chain literature. This paper reviews supply chain resilience literature that focuses on resilience modeling and quantification and connects the supply chain to other networks, including transportation and command and control. We observe a fast increase in the number of relevant papers (only 47 relevant papers were published in 2007-2016, while 94 were found in 2017-2019). We observe that specific disruption scenarios are used to develop and test supply chain resilience models, while uncertainty associated with threats including consideration of "unknown unknowns" remains rare. Publications that utilize more advanced models often focus just on supply chain networks and exclude associated system components such as transportation and command and control (C2) networks, which creates a gap in the research that needs to be bridged. The common goal of supply chain modeling is to optimize efficiency and reduce costs, but trade-offs of efficiency and leanness with flexibility and resilience may not be fully addressed. We conclude that a comprehensive approach to network resilience quantification encompassing the supply chain in the context of other social and physical networks is needed to address the emerging challenges in the field. The connection to systemic threats, such as disease pandemics, is specifically discussed.
\end{abstract}

Keywords Resilience $\cdot$ COVID $\cdot$ Supply chain $\cdot$ Risk $\cdot$ Policy $\cdot$ Epidemics

\section{Introduction}

\subsection{Supply chain resilience}

Electronic supplementary material The online version of this article (https://doi.org/10.1007/s10669-020-09777-w) contains supplementary material, which is available to authorized users.

Igor Linkov

Igor.Linkov@usace.army.mil

Maureen S. Golan

maureengolan@gmail.com

Laura H. Jernegan

Laura.jernegan@gmail.com

1 Contractor US Army Corps of Engineers, Air Tight Consulting, LLC., Pittsburgh, PA, USA

2 Risk and Decision Science Lead, US Army Engineer Research and Development Center, US Army Corps of Engineers, 696 Virginia Rd., Concord, MA 01742, USA
Supply chain disruptions arise from a "combination of an unintended and unexpected triggering event that occurs somewhere in the upstream supply chain (the supply network), the inbound logistics network, or the purchasing (sourcing) environment, and a consequential situation, which presents a serious threat to the normal course of business operations of the focal firm" (Bode and MacDonald 2017). Disruptions, whether natural or human-caused, are an inherent part of the global context of all supply chains-regardless of the niche market in which those supply chains operate or the critical nature of the goods and services they provide. Studied disruptions have traditionally included localized events, such as the 2019 wildfires in Australia (Edwards 2020) or the 9.0 magnitude earthquake which hit Japan in 
March 2011, causing the Fukushima Daiichi Nuclear Power Plant explosion (National Geographic 2011; World Nuclear Association 2018). The earthquake not only caused damage in Japan, but the effects of the rolling blackouts traveled through global supply chains, necessitating the temporary closure of a General Motors truck plant in Louisiana, for example, due to a lack of Japanese-made parts (Lohr 2011). The COVID-19 pandemic is a disruption of an entirely unprecedented magnitude, which is testing the resilience of global supply chains. The ability for a supply chain's operators to effectively plan, enabling a means for the supply chain to absorb, recover from, and adapt to disruptions of various lengths, impacts, and probabilities, is essential to ensuring the supply chain's function and success. Measuring such abilities provides insights into strengths and deficits and can help focus future planning efforts.

A resilient supply chain is able to recover from the negative impacts of unknown disruptions and adapt to uncertain future events. While a number of definitions of resilience exist within the literature, the National Academy of Sciences (NAS) definition takes the most holistic, comprehensive approach to defining resilience and how it can be quantifiably modeled. According to NAS, resilience is "the ability to prepare and plan for, absorb, recover from, and more successfully adapt to adverse events" (National Research Council 2012). For a supply chain, resilience measures the ability to prepare for and provide essential functions during a disruption, and then to recover from and adapt postdisruption into a form that is better suited to the new "present." Although sustainability, robustness, risk mitigation, leanness, and other supply chain management practices are important for business success, supply chain resilience is unique in its focus on recovery following a disruptive event.

Innovation in supply chain management generates positive risk management capabilities and ultimately a competitive advantage (Kwak et al. 2018). In an ever-evolving global market, supply chain managers have found advantages through supply chain integration, collaboration, and sustainability, often with a focus on creating a "lean" (i.e., efficient) supply chain. However, these innovations may not all support supply chain resilience. For instance, the move towards lean supply chains reduces storage costs by increasing dependency on other components of the supply chain and further compounds disruption propagation (Otto et al. 2017). Resilience may also be built from redundancy and/or adaptive capacity within supply chains, jeopardizing engineering efficiency (Dalziell and McManus et al. 2004; Ganin et al. 2017). Trade-offs are a natural element of any network but must be factored into decision-making appropriately. A resilience-based supply chain model emphasizes such tradeoffs and provides a holistic, comprehensive approach to supply chain decision-making. Because no supply chain is completely independent throughout all nodes and consequently disruptions, such decisions must be contextualized by both a business' singular supply chain and its larger network interactions through resilience analytics. Therefore, this review uniquely addresses the gap in the literature of modeling supply chain network dependence on other networks (e.g., transportation, command and control), which is underscored by the cascading failures caused by the COVID-19 pandemic and inability of supply chains to plan, absorb, recover, and adapt.

Traditionally, a supply chain's vulnerability is the highest when both impact and likelihood of disruption is high (Sheffi and Rice 2005), but in an increasingly complex network of supply chains and changing global demands and probabilities of disruption, how does a disruption of one supply chain affect the network as a whole? How can one supply chain remain resilient in the face of cascading failure of other supply chains, especially as many supply chains are optimized for efficiency and not resilience?

\subsection{Supply chain and systemic threats in the context of pandemics}

Although many disruptions require resilience in only a single supply chain, pandemics and other systemic threats disrupt an entire supply network, including multiple supply and value chains in a short period of time. Epidemics and pandemics strain not only medical supply chains that must ramp up capacity, but also test the resilience of the global supply network. As supply chains specific to the medical field fighting the epidemic(s) may need to ramp up production, other supply chains that are generally optimized for efficiency and not resilience face disruptions of a global magnitude. Existing supply chain literature on epidemics and pandemics focuses on the medical supply chain itself, with little literature focused on the systemic threat of global supply chains throughout a large-scale disease outbreak.

Some of the existing literature on supply chain resilience categorize infectious disease within the same category as natural disasters, grouping together such disruptions as Hurricanes Katrina and Rita on the US Gulf Coast in 2005, the 2003 SARS virus, mad cows disease, the 2001 anthrax attacks and the 2009 swine flu (Bhattacharya et al. 2013). Bhattacharya et.al. does proceed to differentiate these natural disruptions by load types, which are important distinctions for modeling network resilience and ultimately set apart epidemic supply chain stressors: "(i) natural calamities (point load); (ii) infectious diseases (distributed load); (iii) economic recession, inflation in currency (distributed load); (iv) market fluctuations (distributed load); (v) psychological panic among customers (impact load)" (Bhattacharya et al. 2013). Although not discussing epidemics or pandemics specifically, four of the five disruptions are clearly related to epidemic disruptions. This breakdown of pandemics into 
smaller disruption sectors shows the myriad of disruption impacts possible and inherent in pandemics, necessitating the need for resilience analytics across broad sectors and networks.

Sheffi (2015) specifically discusses flu pandemics as supply chain risks, differentiating between other disruptions in that the very nature of an epidemic threatens not only human life, but the foundation of the global supply network-the free movement of people and goods. Sheffi continues to demarcate a distinct difference between a localized disruption (natural disaster, industrial accident, terrorist strike, etc.) and a global crisis such as a pandemic, which simultaneously impacts multiple countries and multiple industries; the fear of contagion results in unanticipated market trends, such as price spikes and hoarding, while demand in other industries is reduced (Sheffi 2015). Along the same lines, Ivanov (2020) more specifically characterizes the risk imposed by epidemics on supply chains by three components: "(i) long-term disruption existence and its unpredictable scaling, (ii) simultaneous disruption propagation in the SC (i.e., the ripple effect) and epidemic outbreak propagation in the population (i.e., pandemic propagation), and (iii) simultaneous disruptions in supply, demand, and logistics infrastructure." Epidemics and pandemics are unique disruptions in that they are both an internal and external systemic threat to almost all supply chains. As suppliers, transportation, and the command and control network, for example, have all been disrupted in the course of an epidemic, robust resilience analytics are essential in order to avoid catastrophic failure.

This interconnection can be exemplified by the fact that one supply chain's product might be another supply chain's strategy to absorb a disruption and prevent further network disruption. For example, in the 2003 SARS epidemic, in the face of most airlines cutting flights to and from Southeast Asia, DHL International Ltd. continued serving their clients and achieved several months of record business because their employees were given personal protective equipment (Sheffi and Rice 2005). However, by restricting travel to many areas during a pandemic or simultaneous epidemic, DHL's supply chain may not have been as resilient and personal protective equipment not as readily available from other supply chains.

In the case of the COVID-19 pandemic, viable treatment options are dependent on: (1) the efficacy of the drug itself and (2) the ability of the supply chain to withstand demand. For example, ribavirin is promoted by some epidemiologists for its in vitro capabilities against the virus, but also for its existing inventory and reliable supply chain (Khalili et al. 2020). Other direct medical supply chains such as Personal Protective Equipment (PPE) have also been strained and may be considered failed as demand is not met (WHO 2020). In the U.S., prior to the COVID-19 pandemic, it was noted that the PPE supply chain would be unable to meet demand should a public health emergency arise (Patel et al. 2017). Patel et al. analyze the medical supply chain during both the 2009 H1N1 and 2014 Ebola epidemic responses, finding that the private and public sectors must work in tandem to ensure agility in supply chains and that demand is met during national disasters (2017). As forewarned, the COVID-19 pandemic is experiencing dramatic PPE shortages worldwide. A case study from the Republic of Ireland indicates that in the face of inadequate PPE supply chains, the healthcare industry is forced to rely upon contingency plans ranging from bespoke production to resorting to re-use of medical equipment (Rowan and Laffey 2020). As this supply chain fails, other supply chains are also directly and indirectly affected.

Government oversight is one viable option for ensuring that essential supply chains do not fail during threats such as pandemics. This option utilizes a similar system to the financial stress test imposed on U.S. and E.U. banks after the financial crisis of 2008 (Simchi-Levi and Simchi-Levi 2020). A simple resilience test should be enforced to ensure that critical supplies are available during and immediately after disruptive events, quantifying "time to survive (TSS)" and "time to recover (TRR)," verifying that practices are in place to ensure that TSS is greater than TRR (Simchi-Levi and Simchi-Levi 2020). Overarching regulation could ensure that one supply chain failure does not necessarily cause a cascading failure across fragile supply chain networks, as during the COVID-19 pandemic. Should supply chain regulation be enforced, enforcement agencies must consider insights gained from the literature on resilience analytics and global supply chains. These "intertwined supply networks (ISN)" (Ivanov and Dolgui 2020) must be modeled with all their network interactions to accurately portray epidemic outbreaks. Therefore, we provide a literature review spanning the current state of resilience analytics in supply chain modeling.

\subsection{Scope of this review}

This paper updates our previous literature review (Mersky et al. 2020), which focused on supply chain resilience literature published from 2007 to 2017, by surveying the burgeoning collection of literature on supply chain resilience from 2017 to 2019. Combining the data resulted in an increase of relevant papers from 47 in Mersky et al. to 141, as this study found 94 new, unique papers, showing significant momentum in the field. In addition, the increased body of papers and additional two years allows analyses of emerging trends in the literature while the previous review, as well as other reviews in the field, operate within smaller or dated literature databases. 
Similarly to Mersky et al. (2019), this paper analyzes how each publication defines and addresses resilience while also assessing how disruptions are modeled, and whether explicit resilience metrics are leveraged. In addition, we have added analyses of geographical distribution of data used in source papers, as well as analyses of trends in publication scope and focus.

\subsection{Current state of supply chain resilience literature review publications}

The explosion in supply chain resilience literature resulted in multiple literature reviews published from 2017 to 2019 . Table 1 provides a summary of the 23 literature reviews published during these years and if/how each one addresses the six categories examined in our review (see SI section for 12 literature reviews published between 2007 and 2016).

The number of literature reviews analyzed in this paper nearly double compared to the analysis of papers published between 2007 and 2016. This increased number of publications in the field reflects the growing interest in, as well as complexity of, supply chain resilience. Nevertheless, none of these reviews is similar in scope to what is presented here. Two of the literature reviews touched on each of the categories analyzed in this paper (Hosseini et al. 2019a, b; Ribeiro and Barbosa-Povoa 2018). Both Hosseini and Ribeiro discuss emerging supply chain resilience modeling trendsfrom 2002 to 2017, and from 2003 to 2013, respectively. Ribeiro calls for further development of holistic modeling approaches, while Hosseini narrows in on an Operations Research approach with a recommendation on the development of a multi-objective two-stage stochastic model to build resilience capacity.

While seven of the literature reviews examined an aspect of geography in relation to supply chain resilience literature, the majority focused on the country of origin of the authors, rather than the source of data/supply chain. Approximately one-third of the literature reviews focused on a unique aspect of supply chain resilience, some as specific as criminality in food supply chains (Fassam and Dani 2017), bioenergy production (Deprá et al. 2018), counterfeit medicines (Pinho de Lima et al. 2018), or the water, energy, food nexus (Namany et al. 2019); the other two thirds of the literature reviews focused on supply chain resilience more generally (Ali et al. 2017; Datta 2017; Ivanov 2017).

\section{Methods}

This publication follows the bibliometric methods of our previous review conducted for 2007-2017 (Mersky et al. 2020) reprinted in the Supplemental Information (SI) section. This review is done for 2017-2019 (publications for the year 2017 were not fully accounted for in Mersky et al (2020) since only 5 papers from 2017 were included, whereas the current count for 2017 is 42 . The 94 articles identified in this review provide the foundation for the results below and are compared with the 47 articles reviewed in Mersky et al. and published between 2007 and 2016, allowing for 12 years of the supply chain resilience field of research to be analyzed, likely from its very beginning.

\subsection{Review process and inclusion criteria}

The bibliometric review began by using the Web of Science (WOS) "All Databases" search tool. The search was conducted the first week of January 2020 to accurately capture publications in the field for 2017 and 2018; the number of papers reviewed for 2019 may be underestimated.

The Web of Science "All Databases" search indicates continued growth in the number of articles published in the field of supply chain resilience. Since 2007, the share of publications discussing resilience within the supply chain literature has increased from $0.1 \%$ in 2007 to $3 \%$ in 2019 (Fig. 1a). Although these publications have not been individually vetted for relevance to "resilience" and "supply chain" they have been tagged with these keywords in the Web of Science database. The upward trend according to the keywords shows an expansion of the two fields, regardless of if the publications are correctly using the two topics. (See SI Table 1 for raw data.)

Next, to ensure the articles were significant for the field, all the English language publications found under the Topic Search = ("supply chain" AND "resilien*") were filtered using the citation requirements listed in Table 2.

Figure 2 illustrates the search process of this literature review. Of the 618 publications from the WOS search, 220 publications met citation requirements. These articles were screened for relevance, yielding 89 articles. All the articles that were not duplicates, literature reviews, books, or introductions that met the citation requirements and were available to the authors through traditional search engines, were reviewed for relevance. This insured that only publications that specifically address supply chain resilience in a rigorous manner were analyzed. For example, many papers tagged as "resilient" actually analyze risk or sustainability.

In addition, of the 220 publications, 23 were identified as literature reviews, and 35 were unavailable through standard search engines. All 23 literature reviews were subjected to a "Forward Backward" search to ensure that any papers offering significant contributions in the field but not coded for "supply chain" AND "resilien*" in the original WOS search were not missed. Of the over 3,000 publications in this step, 318 met citation requirements, with many found to be duplicates, unavailable, or literature 
Table 1 Summary of reviewed supply chain resilience literature reviews

\begin{tabular}{|c|c|c|c|c|c|c|}
\hline Paper & $\begin{array}{l}\text { Uses NAS defini- } \\
\text { tion of resilience, or } \\
\text { equivalent }\end{array}$ & $\begin{array}{l}\text { Addresses SC } \\
\text { modeling/simula- } \\
\text { tion }\end{array}$ & $\begin{array}{l}\text { Addresses SC } \\
\text { dependency on } \\
\text { other networks }\end{array}$ & $\begin{array}{l}\text { Addresses } \\
\text { metrics for } \\
\text { resilience }\end{array}$ & $\begin{array}{l}\text { Addresses } \\
\text { disruption } \\
\text { modelling }\end{array}$ & $\begin{array}{l}\text { Includes geographic } \\
\text { analysis }\end{array}$ \\
\hline $\begin{array}{l}\text { Bogataj and Bogataj } \\
\text { (2019) }\end{array}$ & No & Yes & Yes & No & No & No \\
\hline Gligor et al. (2019) & Yes (P\&H 2009) & No & No & No & No & No \\
\hline $\begin{array}{l}\text { Hosseini et al. } \\
\qquad(2019 a, b)\end{array}$ & $\begin{array}{l}\text { Yes/No go through } \\
\text { resilience defini- } \\
\text { tion, but then } \\
\text { make a new } \\
\text { concept called } \\
\text { "resilience capac- } \\
\text { ity" }\end{array}$ & Yes & Yes & Yes & Yes & $\begin{array}{l}\text { Yes (contributing } \\
\text { authors/organiza- } \\
\text { tions) }\end{array}$ \\
\hline $\begin{array}{l}\text { Namany et al. } \\
(2019)\end{array}$ & No & Yes & Yes & No & No & No \\
\hline $\begin{array}{l}\text { Oliveira et al. } \\
(2019)\end{array}$ & $\begin{array}{l}\text { Yes, list a lot of } \\
\text { author definitions, } \\
\text { including } \mathrm{P} \& \mathrm{H}, \\
\text { only barely say } \\
\text { "plan" }\end{array}$ & Yes & Yes & No & No & $\begin{array}{l}\text { Yes (first author/ } \\
\text { organization) }\end{array}$ \\
\hline Panetto et al. (2019) & No & Yes & Yes & No & Yes & No \\
\hline Bak (2018) & No & Yes & No & No & No & $\begin{array}{l}\text { Yes (countries stud- } \\
\text { ied and authors/ } \\
\text { organizations) }\end{array}$ \\
\hline $\begin{array}{l}\text { Behzadi et al. } \\
\text { (2018) }\end{array}$ & No & Yes & Yes & Yes & Yes & No \\
\hline $\begin{array}{l}\text { Ciccullo et al. } \\
\text { (2018) }\end{array}$ & No & Yes & No & No & No & No \\
\hline Deprá et al. (2018) & No & No & No & No & No & No \\
\hline Dolgui (2018) & No & Yes & No & No & Yes & No \\
\hline Ivanov (2018) & No & Yes & Yes (C2 only) & No & Yes & No \\
\hline $\begin{array}{l}\text { Pinho de Lima et al. } \\
\text { (2018) }\end{array}$ & $\begin{array}{l}\text { Yes (use P\&H and } \\
\text { others collec- } \\
\text { tively) }\end{array}$ & No & No & No & No & $\begin{array}{l}\text { Yes (regions studied } \\
\text { and authors/organ- } \\
\text { izations) }\end{array}$ \\
\hline $\begin{array}{l}\text { Ribeiro and } \\
\text { Barbosa-Povoa } \\
\text { (2018) }\end{array}$ & $\begin{array}{l}\text { Yes (readiness, } \\
\text { response, recov- } \\
\text { ery, growth) }\end{array}$ & Yes & Yes (C2 only) & Yes & Yes & $\begin{array}{l}\text { Yes (corresponding } \\
\text { author/organiza- } \\
\text { tion) }\end{array}$ \\
\hline $\begin{array}{l}\text { Stone and Rahimi- } \\
\text { fard (2018) }\end{array}$ & Yes & Yes (very minorly) & No & Yes & No & No \\
\hline Ali et al. (2017) & Yes & No & No & No & Yes & No \\
\hline Datta (2017) & Yes & Yes & No & No & Yes & No \\
\hline $\begin{array}{l}\text { Fassam and Dani } \\
\text { (2017) }\end{array}$ & No & No & No & No & No & No \\
\hline $\begin{array}{l}\text { Graça and } \\
\text { Camarinha-Matos } \\
(2017)\end{array}$ & $\begin{array}{l}\text { No (absorb and } \\
\text { recover only) }\end{array}$ & Yes & Yes (C2 only) & Yes & No & No \\
\hline Ivanov (2017) & No & Yes & No & Yes & Yes & No \\
\hline $\begin{array}{l}\text { Linnenluecke } \\
\text { (2017) }\end{array}$ & No & No & No & No & No & No \\
\hline $\begin{array}{l}\text { Rajagopal et al. } \\
\text { (2017) }\end{array}$ & No & Yes & Yes (C2 only) & No & Yes & No \\
\hline Smart et al. (2017) & No & No & No & No & No & $\begin{array}{l}\text { Yes (first author/ } \\
\text { organization) }\end{array}$ \\
\hline
\end{tabular}




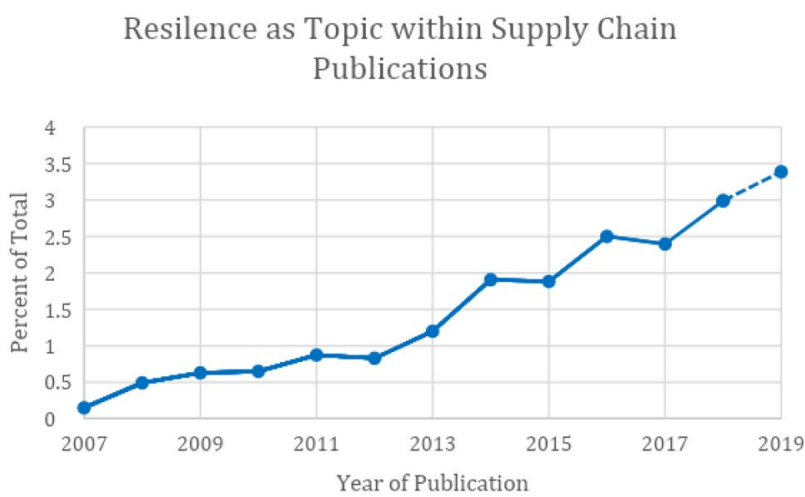

Supply Chain as Topic within Resilience Publications

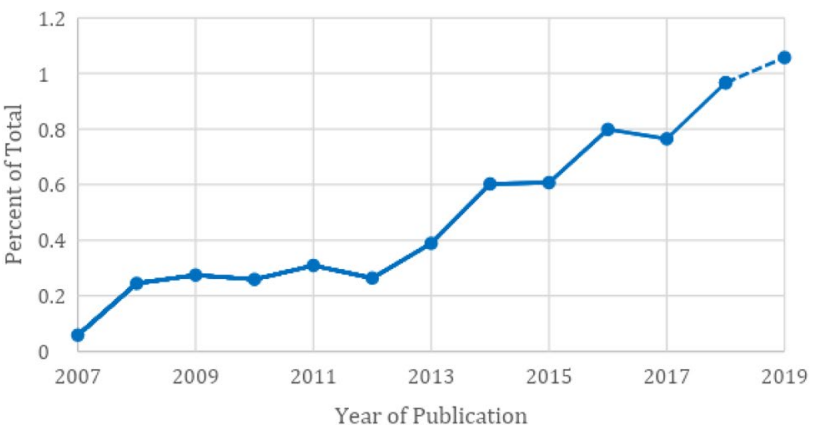

Fig. 1 Share of supply chain publications discussing resilience (a) and share of resilience publications discussing supply chains (b) from WOS April 30, 2020 topic searches. Data for 2019 may be incomplete

Table 2 Citation requirements to ensure only significant articles included for review resulted in

\begin{tabular}{llll}
\hline $\begin{array}{l}\text { Year of } \\
\text { publication }\end{array}$ & $\begin{array}{l}\text { Number of cita- } \\
\text { tions required }\end{array}$ & Original WOS & $\begin{array}{l}\text { Publications with } \\
\text { citation minimum }\end{array}$ \\
\hline 2019 & 2 & 220 & 53 \\
2018 & 4 & 233 & 87 \\
2017 & 5 & 165 & 80 \\
Total & - & 618 & 220 \\
\hline
\end{tabular}

reviews. Overall, the "Forward Backward" search yielded an additional five papers found to be relevant to this review. The additional papers identified through the "Forward Backward" search were subjected to the same citation criteria. The complete search process for 2017-2019 produced a total of 94 relevant articles.

\subsection{Coding scheme and classification process}

Next, all relevant articles were subjected to the coding scheme developed in Mersky et al. 2020 (see SI for details) with the addition of "proxy" to the "resilience metric" expression and a "geo-economic" category to the "disruption representation" expression:

1. Resilience Characteristics

a. Do the authors use all phases of the National Academies of Science resilience definition?

b. Do the authors develop/model a supply chain resilience metric or resilience proxy?

2. Supply Chain Model

a. What type of graphical representation do the authors attribute to the supply chain modeled?

3. Transportation Model

a. What type of graphical representation do the authors attribute to the transportation network? Do the authors account for disruption within the transportation network and its impact on the supply chain?

4. Decision Control

a. How do the authors model supply chain decisions?

5. Disruption Representation

a. How do the authors test for supply chain resilience?

b. What type of data do the authors use in the model? (Quantitative or qualitative)

c. Is the data used country-specific? If so, is it a domestic or international supply chain model? Is the data from a developed or emerging economy?

Additional information about the coding scheme can be found in the Coding Scheme section of the SI document.

\section{Results and discussion}

\subsection{Overall increase in the number of resilience and supply chain publications}

Our study found that publications relevant to the supply chain resilience field are increasing in the literature (Fig. 3). The decline in 2019 may be explained by stringent citation requirements as a similar effect was observed in our previous review (we identified five relevant papers for 2017 in January 2018 while actual number assessed in 2020 is 42). 
Fig. 2 Search Process in Web of Science (WOS)

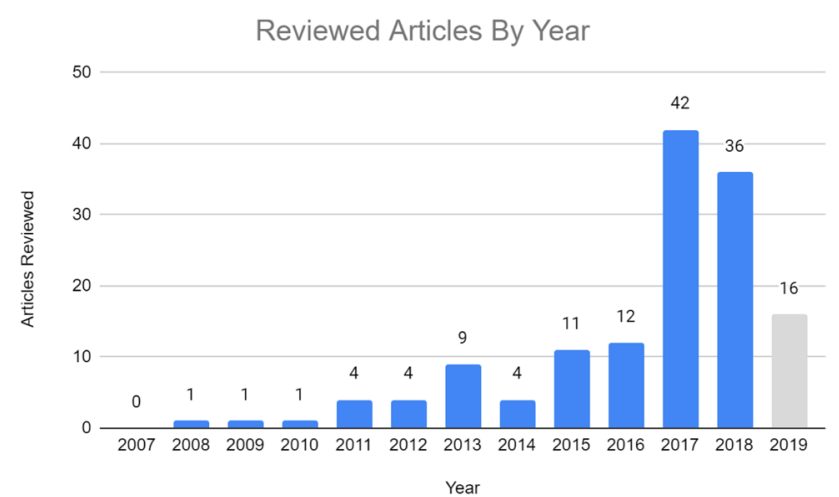

Fig. 3 Reviewed Articles by Year (2019 may be underrepresented due to requirements of two citations per paper and incomplete paper representation given January 2020 search time)

\subsection{Article classification}

Table 3 summarizes the coding classifications given to the 94 2017-2019 reviewed publications as well as for the 47 papers reviewed in Mersky et al. (2020) published in 2007-2016. The five characteristics address: (1) the scope of resilience representation in the supply chain considered, (2) the network structure of the supply chain used, (3) consideration of transportation as a separate network to the supply chain network, (4) consideration of the information network, specifically its use for supply chain control, and (5) representation of the disruption in supply chain modeling considered in the study. Although some publications did not specifically define each component, or even graphically build the supply chain under investigation, it was possible to discern how these components were analyzed and modeled. Table 3 summarizes each classification that was considered to be an important aspect of modeling supply chain resilience; defining and developing each component of the supply chain's network is vital for achieving progress in the field. Corresponding characteristics and trends are discussed in the following sections.

We find that the lack of consensus on definitions and resilience metrics has evolved into a trend of using "proxies" rather than explicit metrics for measuring supply chain resilience. We find that although some authors claim the models they develop measure supply chain resilience, the outputs of the models present indirect measurements of resilience, that must then be further correlated to supply chain resilience. These proxies provide important measurements and components of both resilience and supply chain performance, but the model does not provide an integrated quantification of supply chain resilience. Additional themes also emerged during this analysis, such as an overwhelming emphasis on individual supply chain nodes, qualitative frameworks for resilience strategies, and geographical diversity of supply chain resilience literature in both developing and emerging economies. Consistently missing is the integration of a comprehensive approach to network resilience throughout all nodes of the supply chain and levels of the supply chain network which includes definitions, models, metrics, and disruption analysis.

\subsection{Trends in supply chain resilience quantification}

\subsubsection{Integration of components of resilience in general}

While much of the recent literature discusses resilience in terms similar to the four resilience characteristics defined by NAS (plan, absorb, recover, adapt), a number of authors focus on individual elements and do not offer a comprehensive understanding of supply chain resilience in their models and metrics. In order to advance resilience analytics, and 
Table 3 Number of articles reviewed addressing each category

\begin{tabular}{|c|c|c|c|c|}
\hline & & & 2017-2019 & $2007-2016$ \\
\hline \multirow[t]{5}{*}{ Resilience characteristics } & Plan & Uses NAS phase of resilience & 65 & 41 \\
\hline & Absorb & Uses NAS phase of resilience & 67 & 44 \\
\hline & Recover & Uses NAS phase of resilience & 72 & 31 \\
\hline & Adapt & Uses NAS phase of resilience & 54 & 17 \\
\hline & Resilience Metric or "Proxy" & $\begin{array}{l}\text { Numeric measure of resilience, separate from } \\
\text { network characteristic }^{\mathrm{a}}\end{array}$ & 45 & 31 \\
\hline \multirow[t]{4}{*}{ Supply chain model representation } & Linear & Unidirectional and no path options & 10 & 10 \\
\hline & Branching & Unidirectional with path options & 29 & 15 \\
\hline & Graph & Multi-directional with path options & 38 & 17 \\
\hline & Other $^{\mathrm{b}}$ & Different enough to not classify as the others & 17 & 5 \\
\hline \multirow[t]{5}{*}{ Transportation model representation } & None & Disruptions only within SC nodes & 50 & 18 \\
\hline & Same as SC & SC links can be disrupted & 10 & 12 \\
\hline & Independent Links & Independent network for each SC link & 28 & 10 \\
\hline & Graph & $\begin{array}{l}\text { Can be adjusted dynamically-SC nodes } \\
\text { placed on a single transportation network }\end{array}$ & 5 & 5 \\
\hline & Other & Different enough to not classify as the others & 2 & 2 \\
\hline \multirow[t]{5}{*}{ Command and control representation } & None/Pre-determined & $\begin{array}{l}\text { Decisions on production and movement will } \\
\text { not change }\end{array}$ & 20 & 4 \\
\hline & If-then/Heuristic & $\begin{array}{l}\text { Discrete, deterministic and simple rules for } \\
\text { decision at each SC node; explicit guidance } \\
\text { for managerial implications presented }\end{array}$ & 18 & 5 \\
\hline & Agent Based & $\begin{array}{l}\text { Probabilistic and/or complex made by multiple } \\
\text { independent actors }\end{array}$ & 13 & 5 \\
\hline & Optimization & $\begin{array}{l}\text { Optimization algorithm employed to ensure } \\
\text { "best" decisions made }\end{array}$ & 38 & 31 \\
\hline & Other & Different enough to not classify as the others & 6 & 2 \\
\hline \multirow[t]{5}{*}{ Disruption representation } & Case Study & $\begin{array}{l}\text { Real world circumstances used to model } \\
\text { disturbances }\end{array}$ & 44 & 15 \\
\hline & Set List & Pre-determined list of disturbances generated & 10 & 26 \\
\hline & Monte Carlo & Disturbances randomly generated & 11 & 7 \\
\hline & Targeted & $\begin{array}{l}\text { Adversarial algorithm used to generate distur- } \\
\text { bances }\end{array}$ & 5 & 1 \\
\hline & None/Other & Different enough to not classify as the others & 25 & 4 \\
\hline
\end{tabular}

an the 2017-2019 review, "proxy" was added as a way to differentiate between the numeric measure of supply chain resilience and other factors being used to measure supply chain resilience (e.g., disruption cost, product depreciation, time to receive a good, etc.). Of the 45 publications shown to contain a metric, 24 are considered proxy

bIn the 2017-2019 review, "other" encompasses supply chain models that focus more on resilience of the network within external contexts, as opposed to strict definitions and traditional graphic models of supply chains. Of the 17 publications considered other, 9 are considered to model supply chain resilience in relation to other networks, rather than within itself

to accurately model the resilience of supply chains, especially to systemic disruptions, a comprehensive definition of resilience must be used across the literature. Figure $4 \mathrm{a}$ and $b$ analyze the occurrence of the four characteristics of resilience as defined by NAS_ plan, absorb, recover, adapt. Figure $4 \mathrm{a}$ shows the occurrence rate of each characteristic of supply chain resilience in the supply chain resilience publications. If each publication consistently defined and modeled resilience, each of the four bars would be at $100 \%$. Figure $4 \mathrm{~b}$ expresses the number of supply chain resilience characteristics referenced per publication reviewed (0 to 4 ).
As is evident in Fig. 4b, more than half of the papers reviewed neglected to include all four characteristics of resilience within the definition or understanding of the concept of supply chain resilience put forth versus about $30 \%$ just two years prior. One example is Kristianto (2017), who defined the goal of a resilient global manufacturing supply chain to be simply reaching a stable condition following internal or external changes affecting system performance. Although it can be inferred that this definition encompasses the absorb and recover characteristics of resilience, little is known about the new "normal" state of the supply chain that emerges following the disruptive event. Another trend 


\section{Supply Chain Resilience Characteristics}

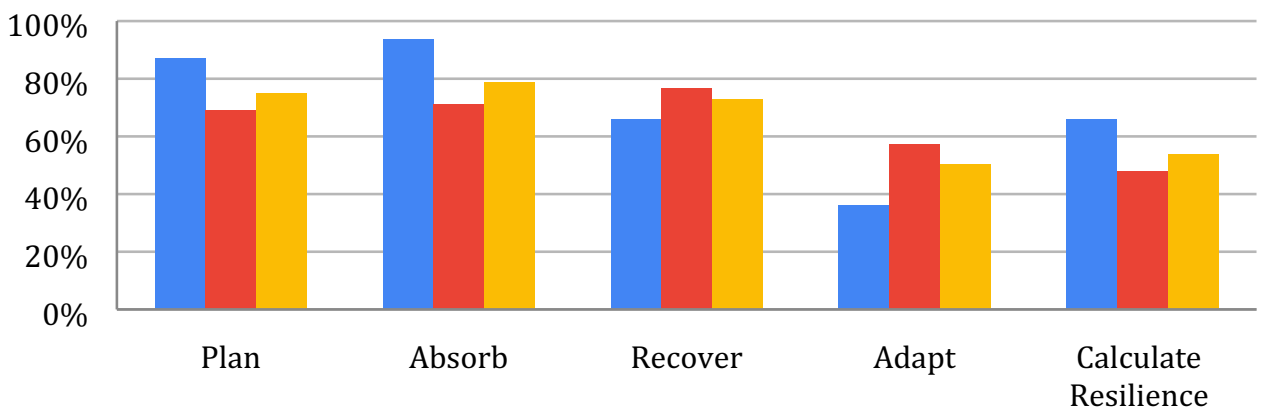

Fig. 4 a Percentage of reviewed publications within each category compared across three time periods (blue $=2007-2016$ normalized by 47 (Mersky et al 2020), red $=2017-2019$ normalized by 94 , and orange $=2007-2019$ normalized by 141). b Percentage of reviewed publications that reverence all 4 characteristics, 3, 2, 1, or 0 characteristics defined by NAS (blue $=2007-2016$ normalized by 47 (Mersky et al 2020), red =2017-2019 normalized by 94 , and orange $=2007-2019$ normalized by 141 )

\section{Characteristics Referenced}

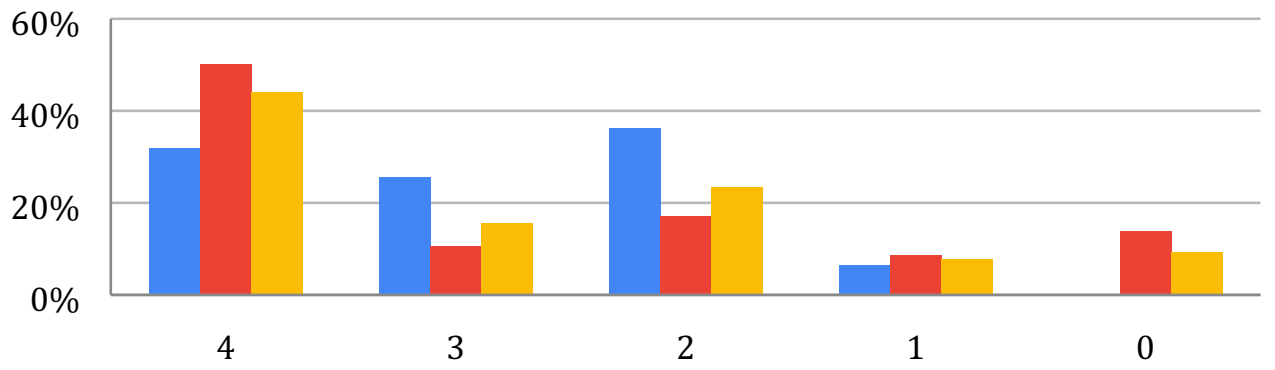

Fig. 4 (continued)

related to the definition of resilience is the frequency of use of the term adapt, but not in the way it is defined by NAS. While NAS uses adapt to indicate how well a supply chain prepares to handle future disturbances following recovery, some of the literature examined used adapt interchangeably with, or as a combination of, absorb and recover, but not in the sense that the supply chain was adapting to a new, future state. Per Fig. 4a, adapt, as defined by NAS, was the least often occurring resilience characteristic within the publications examined.

Furthermore, we found a lack of agreement on the provided definitions of supply chain resilience. Most papers cite unique and sometimes mutually contradictory definitions from different authors and disciplines, seemingly as a way to offer a more comprehensive view of supply chain resilience or as a means for supporting the specific topic of their research. This reflects a general confusion in the literature in defining resilience and other properties characterizing systems affected by threats such as reliability, agility, safety, security, and sustainability, among others (Galaitsi et al. 2020). Of the authors that do offer an explicit definition of supply chain resilience, many revert to the definition provided by Ponomarov and Holcomb (2009) of supply chain resilience as the "adaptive capability of the supply chain to prepare for unexpected events, respond to disruptions, and recover from them by maintaining continuity of operations at the desired level of connectedness and control over structure and function" (Gabler et al. 2017; Khemiri et al. 2017; Yang et al. 2017; Valipour Parkouhi and Safaei Ghadikolaei 2017). A number of other authors frame their research around the proactive and reactive components and strategies of resilience (Cheng and Lu 2017; Dehghani et al. 2018; Zhalechian 
et al. 2018). While these proactive and reactive capabilities and strategies could be interpreted as addressing all four resilience characteristics defined by NAS (plan, absorb, recover, adapt), this conclusion would be drawn only by making a number of inferences and assumptions not explicitly stated by the authors.

Another distinct trend is the inconsistent use of terminology and acronyms. Without specifically classifying supply chain resilience, but addressing themes relevant to the field, the terms Supply Chain Risk System or "SCRS" (Zeng and Yen 2017), Sustainable Supply Chain Management or "SSCM" (Sauer and Seuring 2019), Supply Chain Risk Management or "SCRM" (Kirilaz 2017; Revilla and Saenz 2017), and Supply Chain Network Design or "SCND" (Rezapour 2017) have been used. "Supply chain resilience" has been converted to the following acronyms: "SCR" (Liu 2018 A; Pourhejazy et al. 2017), "SCRE" (Chowdhury and Quaddus 2017), and "SCRES" (Sahu et al. 2017), in addition to Supply Chain Reliability and Resilience or "SCRR" (Chen et al. 2017). This indicates a lack of consensus among researchers as to how to properly classify this field of study and inhibits research because common terminology is not available for comparison and dialogue.

\subsubsection{Supply chain model structure}

A supply chain model represents the physical nodes of a supply chain and how they relate to one another, indicating how both raw materials and information flow. Without the explicit use of network representation terminology, the disruption analyzed is difficult to apply to other supply chains or to use to build the field of resilience analytics. Few of the publications examined explicitly use supply chain representation terminology terms such as "linear," "branching," or "graph" (see details in SI). Therefore, the coding is based on interpretation of the supply chains described and modeled within the publications. The most prevalent supply chain modeled was graph (38 publications), followed closely by branching ( 29 publications), while linear was the least common supply chain model (10 publications) (see Fig. 5). Notably, 13 out of the 94 publications reviewed did not define a specific supply chain model, but rather expanded on the relationship between the supply chain and the network with which it interacts. These papers were coded as "other" for supply chain model. While these authors did not specifically describe the internal supply chain network design, they did quantitatively model disruptions and quantify the impacts of those disruptions to measure network resilience (Bode and MacDonald 2017; Liu 2018). Many other papers discussed a supply chain but focused on qualitative evaluation, primarily identifying themes and best practices (Dubey et al. 2019; Chen et al. 2017).

It is not surprising that linear models are the least common supply chain network representation because these are the most fragile and unrealistic supply chains. For example, if a disruption happens at one node, all of the remaining nodes are completely cut off from their supply. Rerouting is only possible when path options exist, but because linear models offer no path options, a disruption anywhere along the supply chain will halt production and negatively impact performance until the node recovers or a new supply chain is formed. Although linear models may accurately represent some supply chains, they simplify global network interactions that must be accurately modeled to quantify resilience.

Some articles specify the supply chain modeled as "green," "lean," or "sustainable," but make no direct mention of its network representation (Mohammed et al. 2019; Ruiz-Benetiz et al. 2017; Lotfi and Saghiri 2018; Sauer and Seuring 2019). Without a direct correlation to specific supply chain network models, it is not only challenging to use results from one study for another supply chain, but also to quantitatively model supply chain resilience in the first place. All supply chains are different, so a graphical representation allows for cohesive supply chain resilience metrics to be developed. With graphical representations, when supply chain managers seek guidance for increasing the resilience of their supply chains, they are able to
Fig. 5 Percentage of reviewed publications within each category compared across three time periods (blue $=2007-2016$ normalized by 47 (Mersky et al 2020), red $=2017-2019$ normalized by 94 , and orange $=2007-$ 2019 normalized by 141)

\section{Network Representation}

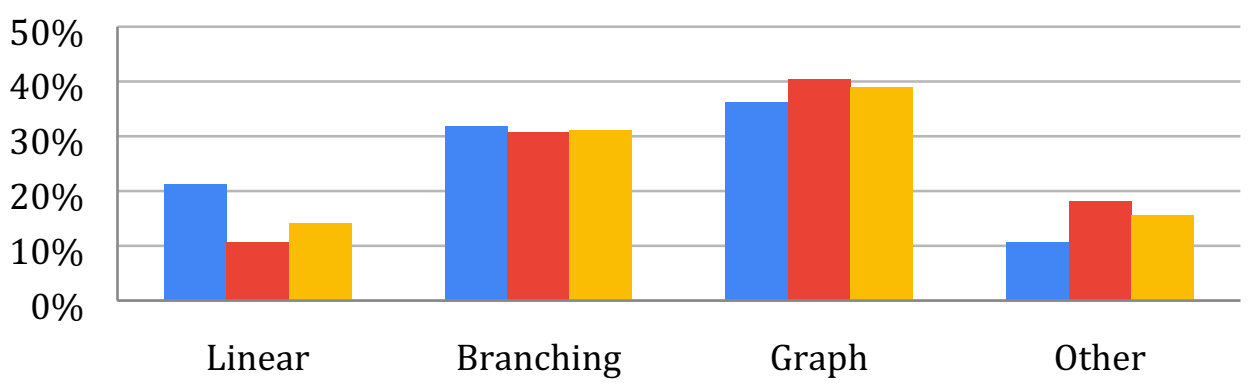


draw connections with supply chain networks with similar designs, representation, and challenges.

\subsubsection{Integration of transportation in supply chain modeling}

Understanding how materials move physically between nodes in a supply chain network is essential for maintaining operations during and after disruptions. This is especially true during a pandemic, when physical contact between humans and materials alike exacerbates the risk of spreading disease. Assessing and planning for optimal efficiency and resilience in the transportation network during a pandemic is a critical step in maintaining a resilient supply chain and a healthy workforce (Ganin et al. 2017). Disruptions can affect connections/links such as supply routes, ports, and transportation services as unexpectedly and devastatingly as they affect individual nodes. These disruptions between nodes are challenging to predict and mitigate due to the multitude of services being conducted simultaneously in various parts of the world, and the physical nature of the transportation network moving goods from one location to another. Without modeling and accounting for the supply chain's dependency on other networks, advanced resilience analytics cannot be achieved. Of the publications that did address the transportation model in relation to the supply chain model, the majority were independent links (27 publications), followed by transportation models coded as same as supply chain (10 publications). For the papers analyzing supply chains with independent link transportation networks, the network is often evaluated in terms of cost (Ramezankhani et al. 2018; Valipour Parkouhi and Safaei Ghadikolaei 2017; Kurniawan et al. 2017), time/distance for travel between nodes (Otto et al. 2017; Ni 2018), or as a component of supplier selection (Valipour Parkouhi et al. 2019).

Additionally, despite the importance of the transportation model within the supply chain network, the majority of publications failed to analyze the transportation network independent of the supply chain itself-over half (50 out of 94 publications) do not address the transportation model upon which the supply chain relied (see Fig. 6). Notably, Khemiri et al. (2017) choose not to model the transportation network, explicitly stating that this is due to its complexity. Similar in result, Namdar et al. (2018) assume a completely reliable transportation network in their model but recommend incorporating resilience in transportation and inventory management. A number of other papers discuss some elements of transportation, but do not model disruptions along the transportation network or consider transportation independently (Lee 2017; Gaustad et al. 2018; Diabat et al. 2019). Supplies and products move between supply chain nodes, directly relying on outside networks, which are themselves prone to disruptions. Therefore, a supply chain cannot achieve resilience without managers integrating the transportation network into the supply chain resilience model. The lack of transportation models within the literature underscores the need for resilience analytics of the supply network in general, and especially under disruptions. Quantifying resilience to systemic threats, such as the COVID-19 pandemic, is particularly important as not only a single supply chain is affected, but a network of supply chains relying on transportation networks.

\subsubsection{Representation of information networks and command and control structures}

While many aspects of the supply chain are now managed according to advancements in technology, a central decision maker remains essential for supply chain function, and ultimately responsible for the application of resilience analytics to the supply chain. As Fig. 7 depicts, 20 of the 2017-2019 papers either ignored the command and control (C2) network completely or assumed that decisions about the supply chain movements would not change (Gabler et al.
Fig. 6 Percentage of reviewed publications within each category compared across three time periods (blue $=2007-2016$ normalized by 47 (Mersky et al 2020), red $=2017-2019$ normalized by 94 , and orange $=2007-$ 2019 normalized by 141)

\section{Transportation Network Representation}

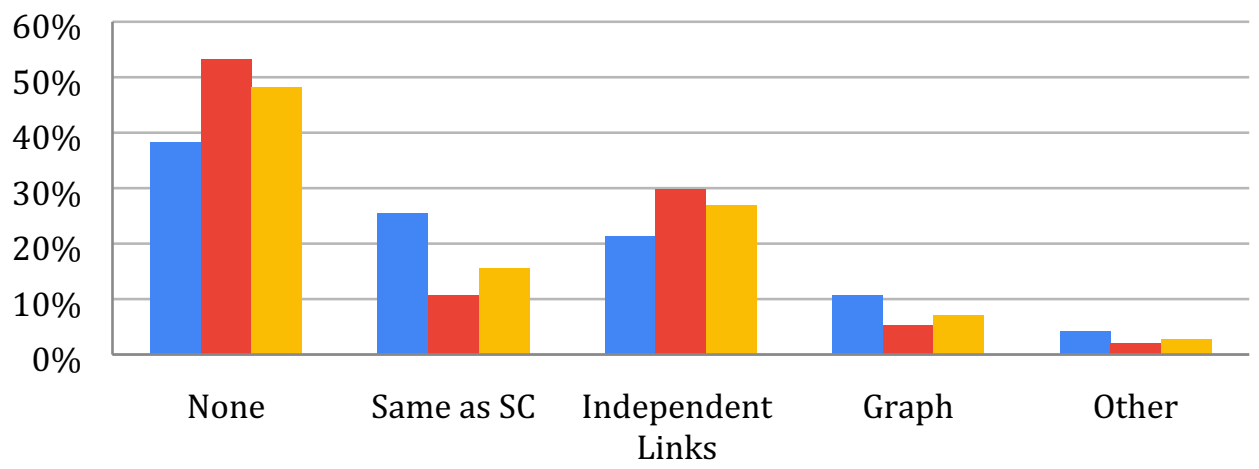


Fig. 7 Percentage of reviewed publications within each category compared across three time periods (blue $=2007-2016$ normalized by 47 (Mersky et al 2020), red $=2017-2019$ normalized by 94 , and orange $=2007-$ 2019 normalized by 141)

\section{Command and Control}

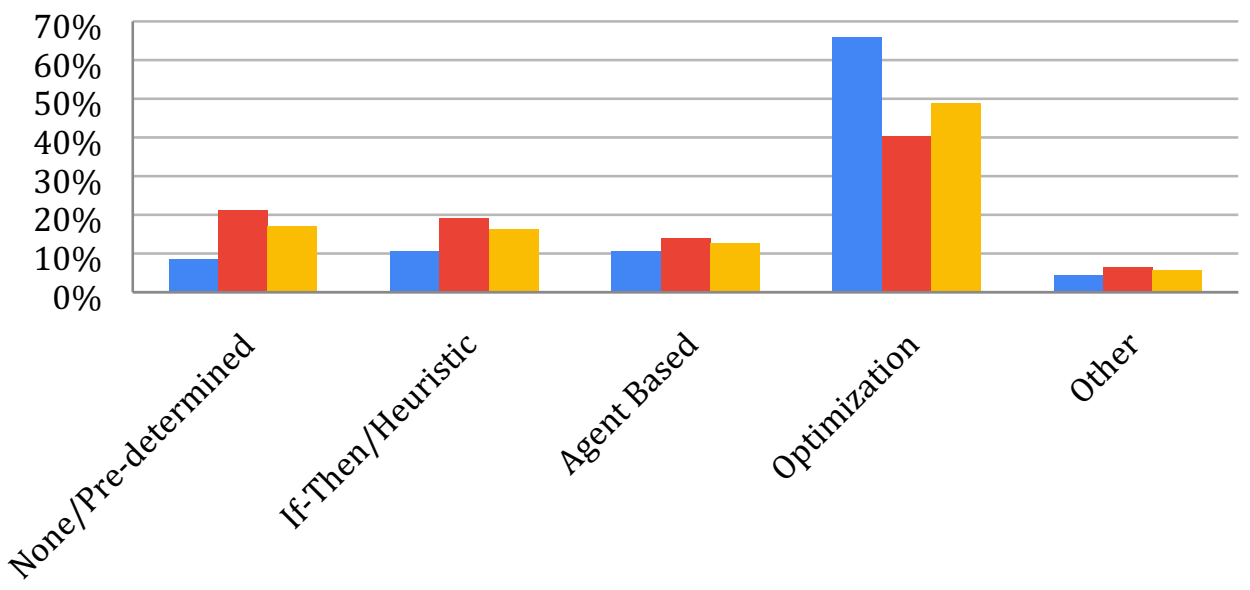

2017; Fattahi et al. 2017). Optimization (38 publications) is the most widely used form of $\mathrm{C} 2$ representation among the publications examined. Optimization is a more robust decision control framework for its ability to combine multiple objectives into network design. However, completely removing the human decision-making element can also create risk. Sahu et al. (2017) address this by combining an optimization model with managerial oversight. In this model, the optimization model solves for the weakest performing area of the supply chain and the manager has to adapt and implement the changes.

The if-then/heuristic model is the next most frequently used $\mathrm{C} 2$ representation (17 publications), and it correlates strongly with publications that put forth specific managerial implications (Kamalahmadi and Parast 2017; Kwak et al. 2018; Li, R. et al. 2017b). Agent Based C2 networks appear 13 times in this review. Rajesh (2018) examines agentbased decision control through four supply chain managerial processes: supplier relations management, customer relations management, internal supply chain management, and managing external environments. In general, the disproportionate emphasis on optimization models evident in the 2007-2016 papers has somewhat diminished in relation to the other C2 models compared to the 2017-2019 papers.

One emerging trend identified from the 2017 to 2019 publications is the move towards more "intelligent" processes, machine learning, the use of big data, digital twins, and other elements of the "fourth industrial revolution" or "Industry 4.0." Cavalcante et al. (2019) combine machine learning and simulation to create digital supply chain twins. Machine learning was coded as other in this review to reflect its significant difference from traditional quantitative optimization techniques used in other publications.

\subsubsection{Modeling disruptions}

The reviewed literature primarily focuses either on lowprobability but high-impact or high-probability but lowimpact disruption scenarios. For example, some publications specifically differentiate between operational risks and disruption risks such as natural disasters, terrorism, and political instability (Namdar et al. 2018; Ramezankhani et al. 2018; Sabouhi et al. 2018). Disruptions in the context of climate change in terms of both slow onsets such as sea level rise and rapid disasters such as severe storms are common themes (Beheshtian et al. 2017, 2018; Dubey et al. 2019; Lim-Camacho et al. 2017; Otto et al. 2017). Beyond physical disruptions, Kwak et al. (2018) analyze exchange rate risk as a disruption (2018) and Mancheri et al. (2019) study the impact of Chinese policies relating to rare earth elements on supply chain resilience. None of the publications meeting the inclusion criteria for this review specifically model pandemics and subsequent supply chain network resilience.

On the other hand, some publications do not provide context for the cause of the disruption, but rather focus on the effects of a disruption. Ghavamifar et al. (2018) analyze the effects of partial and complete disruptions at distribution centers, as well as disruptions taking place between the distribution centers and manufacturing plants, and between distribution centers and resellers along the transportation route. Hosseini et al. (2019a, b model the probability of a disruption and provide decision-makers with strategies for how and when to use both proactive and reactive strategies in supplier selection and order allocation.

Although many authors discuss different types of disruptions within their introduction and/or background sections, the methods for modeling disruptions remain narrow. The top three disruption representations used are 
Fig. 8 Percentage of reviewed publications within each category compared across three time periods (blue $=2007-2016$ normalized by 47 (Mersky et al. 2020), red $=2017-2019$ normalized by 94 , and orange $=2007-$ 2019 normalized by 141)

\section{Disruption Representation}

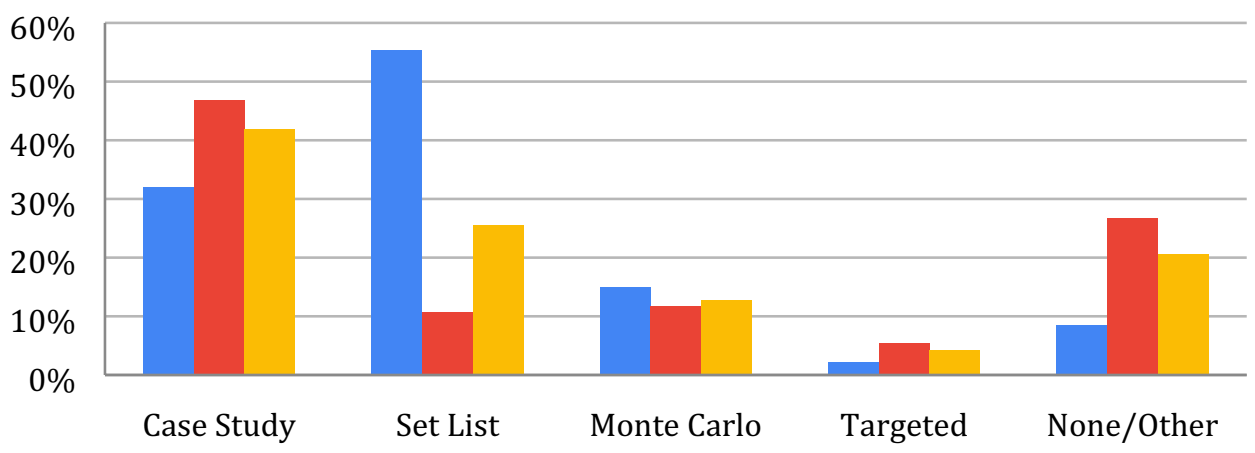

case studies (43 publications), Monte Carlo-generated disruptions (11 publications), and set lists (10 publications) (see SI for classification details). Targeted is the least used form of disruption representation (5 publications). Twenty-one of the publications reviewed do not model a disruption (see Fig. 8). Although case studies are one tool for understanding supply chain resilience models and metrics, they are inherently limited to the disruption scenario presented within the publication. A resilient supply chain must be able to respond to uncertain and unpredictable events, but a case study does not allow for uncertainty to enter the disruption scenario, or for the lessons learned to be applied to a wider variety of locations and/or industries. For example, Maheshwari et al. (2017) base their analysis on the impact of floods on the biofuel supply chain for a region of 13 colonies in southern Illinois. This analysis provides useful insight for this region but may not be easily transferable to other regions or economies.

Many publications also are limited to specific supplier resilience and supplier selection (Kırılmaz \& Erol 2017; Shishodia et al. 2019; Wang et al. 2017; Yoon et al. 2018; Valipour Parkouhi and Safaei Ghadikolaei 2017; Cavalcante et al. 2019), and do not necessarily show the disrupted node's effects when propagated throughout the entire supply chain being modeled or on the resilience of the entire network. Supplier selection is important because suppliers, too, rely on their own supply chains-resilient or not-affecting items such as supply, price, timing, and ultimately the resilience of the supply chains relying on them. Neglecting supplier selection as a variable in these models does not offer a holistic approach toward repercussions within the larger supply network. However, when publications do account for vendors, the authors limit the scope of the supply chain or complexity of disruption, such as material scarcity (Gaustad et al. 2018; Bottani et al. 2019). Gao et al. (2019) acknowledge that disruption scenarios with a higher degree of unknowns must limit the supply chain modeled in order to model the supply chain resilience. As a result, Gao et al. (2019) use Monte Carlo to simulate random vendor disruption but assume independence of each vendor node.

The narrow focus on supply chains analysis within the framework of case studies produces sometimes contradictory conclusions about supply chain resilience. Conz et al. (2017) analyze global and historical trends in the Italian wine industry and find that decreased connectedness increases resilience in the small- and medium-sized markets. On the other hand, Ivanov (2019) finds that isolated optimization of the production and distribution networks decreases supply chain resilience in a non-perishable product manufacturer supply chain with quality problems. Supply chain resilience models and metrics cannot yet be generalized across varying networks and disruptions. Sufficient interacting factors must be identified and consistently considered to render the models more reliable.

\subsection{Measuring and modeling supply chain resilience}

Of the 94 papers found to be relevant for this analysis, $52 \%$ neglect to propose a method for measuring supply chain resilience or focus primarily on qualitative analysis, identifying trends and best practices across a variety of industries. Only $22 \%$ of the papers reviewed provide an explicitly defined measurement for supply chain resilience, while $26 \%$ of the papers reviewed measure resilience proxies. In Mersky et al. (2020) supply chain metrics were found in $70 \%$ of papers. Although publications currently defined as proxy were previously coded as yes (Mersky et al. 2020), the combined results (yes and proxy) of this new review show comparable results to the 2007-2016 review.

This paper defines a resilience proxy as a metric identified in a model that does not quantify supply chain resilience 
directly, but is a component or characteristic of supply chain resilience and is quantitatively leveraged by the authors to compare the effects of certain resilience techniques or tools on the networks. Some of the proxies identified within the literature include: preservation of market share (Rajesh 2018), performance after disruption using backlog as a metric (Li, H. et al. 2017a), product depreciation (Behzadi et al. 2017), readiness (Bode and MacDonald 2017), expected disruption cost (Maheshwari et al. 2017; Zhalechian et al. 2018), total direct losses (Otto et al. 2017), customer retention, i.e., cost of lost customers ( $\mathrm{Ni}$ et al. 2018), delivery delay and fractional quantity loss (Paul et al. 2019), percentage of suppliers who lost capacity under disruption (Sabouhi et al. 2018), recovery rate (Zeng and Yen 2017), expected cost, and carbon emissions (Yavari and Zaker 2019; Zavitsas et al. 2018; Zahiri et al. 2017).

Of the publications reviewed for this current paper that were coded yes for resilience metric, each had a specific model for quantifying resilience. Many of the publications integrated some of the resilience proxies as stated above into a more complex model for measuring resilience, which is the reason they were coded yes for the resilience metric. Chen et al. (2017) presented a framework for evaluating the impact of different risk-mitigation strategies, utilizing a metric for a supply chain's "resilience score." This framework begins with node-level resilience and further propagates the method into the rest of the supply chain via buyer-supplier relationships. Node-level resilience is defined as having three supply chain design elements: reliability, pre-disruption mitigation capabilities (PEDC), and post-disruption mitigation capabilities (PODC) (Chen et al. 2017). Although the analysis begins with a node-level analysis, it progresses to show the importance of integrating a comprehensive approach to resilience throughout all nodes of the supply chain and levels of the supply chain network.

Many authors use multiple objectives in order to assert a comprehensive metric for supply chain resilience. LimCamacho et al. (2017) successfully quantify the impacts of climate shocks within random nodes in six different Australian global resource supply chains (including fisheries, agriculture, and mining), by utilizing the "Supply Chain Index" (SCI) originally put forth by Plagányi et al. (2014) to assert that: supply chain resilience $=1-\mathrm{SCI}$. In this model, higher values reflect improved resilience, as the scores range from 0 (only possible in a linear supply chain) and 1 (maximum resilience) and assert that climate resilience performance $=$ resilience $\times$ continuity $($ Lim-Camacho et al. 2017). Out of all the publications reviewed, this paper offers one of the more straightforward, yet also flexible, metrics for measuring resilience, allowing for the addition of other factors into the calculation of the metric.

\subsection{Data sources and types and linkages with Al}

Most of the publications reviewed include both qualitative and quantitative elements, with 12 publications focused solely on qualitative analysis, generally entailing best practices collected across a wide survey audience or lessons learned from specific events or in niche markets. Examples of specific, niche supply chain resilience research include: Taiwanese manufacturing (Chen et al. 2017), Iranian glass (Jabbarzadeh et al. 2018; Fattahi et al. 2017), and blood supply chain during a humanitarian crisis (Diabat et al. 2019). Papadopoulos et al. (2017) focuses on the lessons learned following the 2015 earthquake in Nepal, with an emphasis on the role of big data. Data were collected from Twitter, various news outlets, Facebook, WordPress, and Instagram, as well as a survey of 205 supply chain managers. The authors conclude that big data (i.e., unstructured data) can be used to test supply chain resilience and that swift trust, public-private partnerships, and quality information sharing are linked to resilience in supply chain networks (Papadopoulos et al. 2017). The wide range of data sources and types is indicative of a lack of consensus as to what data inputs are necessary for modeling supply chain resilience across different networks.

As supply chains become more varied and complex and progress into Industry 4.0, different modeling and managerial techniques are becoming available. For example, biologically-inspired algorithms such as the Ant Colony Optimization, Cuckoo Search, and Particle Swarm Optimization have been reviewed (Byrne et al. 2018), and are likely to represent supply chain disruption as the literature progresses. This is compounded by an emphasis on placing the supply chain into the complex environment in which it exists and the move from "supply chain" to "supply network" as signified by the increasing ability to track, anticipate, and analyze

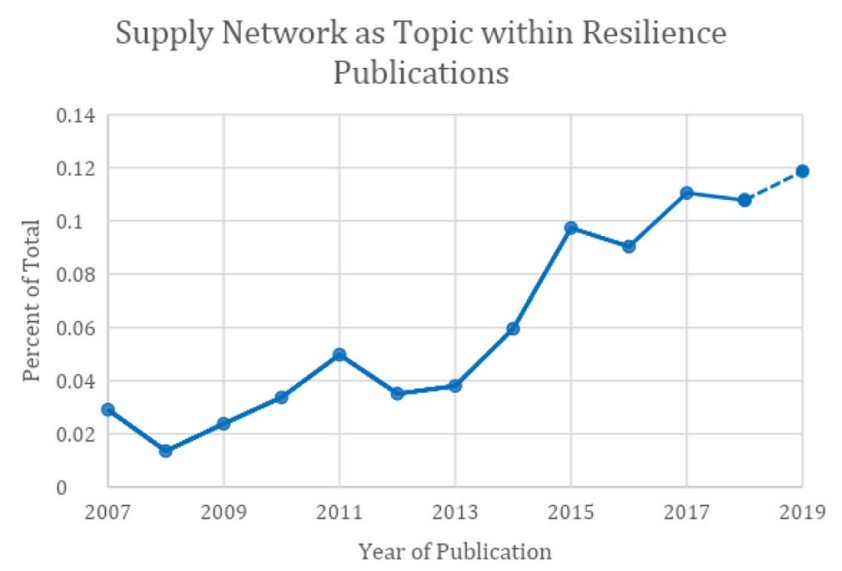

Fig. 9 Share of Supply Network Publications Discussing Resilience from WOS April 30, 2020 topic searches. Data for 2019 may be incomplete 
increasing amounts of data (Otto et al. 2017). Figure 9 shows the increasing number of supply chain network publications discussing resilience over time.

\subsection{Geo-economic analysis}

This literature review further analyzes the geographic differentiation among the publications reviewed that were published between 2017 and 2019. Supply chains, industry types, and disruption threat levels are subject to the location from which they originate and with which they operate. Certain countries or regions are hubs for certain industries, political threats, or climatic threats, and could affect the supply chain resilience models, especially during pandemics. For example, Tukamuhabwa et al. (2017) utilizes a single case study on 20 manufacturing firms in Uganda to identify critical challenges to supply chain resilience in developing, or emerging, economies. Some of these challenges include counterfeiting, dishonest employees, and corruption (Tukamuhabwa et al. 2017). To differentiate between possible geographic specificities, each of the 94 publications was categorized in terms of its geographic location (country/ region), type of economy (developed or emerging), industry, sub-industry, and supply chain scope (domestic or international). Table SI3 includes each of these categories, in addition to the type of data (quantitative, qualitative, or both) and whether or not the publication presents a metric, or proxy metric, for resilience.

Of the 94 publications reviewed, 58 identify specific geographic locations for the supply chains analyzed, coded based either on where the data were collected, or on the location of the case study used for disruption representation. The breakdown between developed and emerging economies was relatively balanced, with 30 publications focusing on developed economies, 27 publications focusing on emerging economies, and 1 publication combining developed and emerging economies. For the purposes of this review, an economy is considered "emerging" if it does not appear on the United Nations list of developed economies (United Nations 2019). The most frequently examined country was the United States (10 publications), followed by Iran (9 publications), India (5 publications), and China (6 publications). The remainder of the publications with specific countries/ regions of focus address supply chains based in Australia, Japan, Bangladesh, Nepal, Vietnam, South Korea, and a mix of European countries, primarily England, France, and Italy. The only supply chain examined quantitatively in Africa was in South Africa and the only supply chains examined quantitatively in Central and South America were in Mexico and Brazil. Figure 10 shows the data origination from publications that reference specific locations, with the colored dots representing the type of industry used for data collection or disruption modeling. Table 4 provides an overview of the primary industries analyzed in the reviewed publications and examples of sub-industries within each of the primary industries.

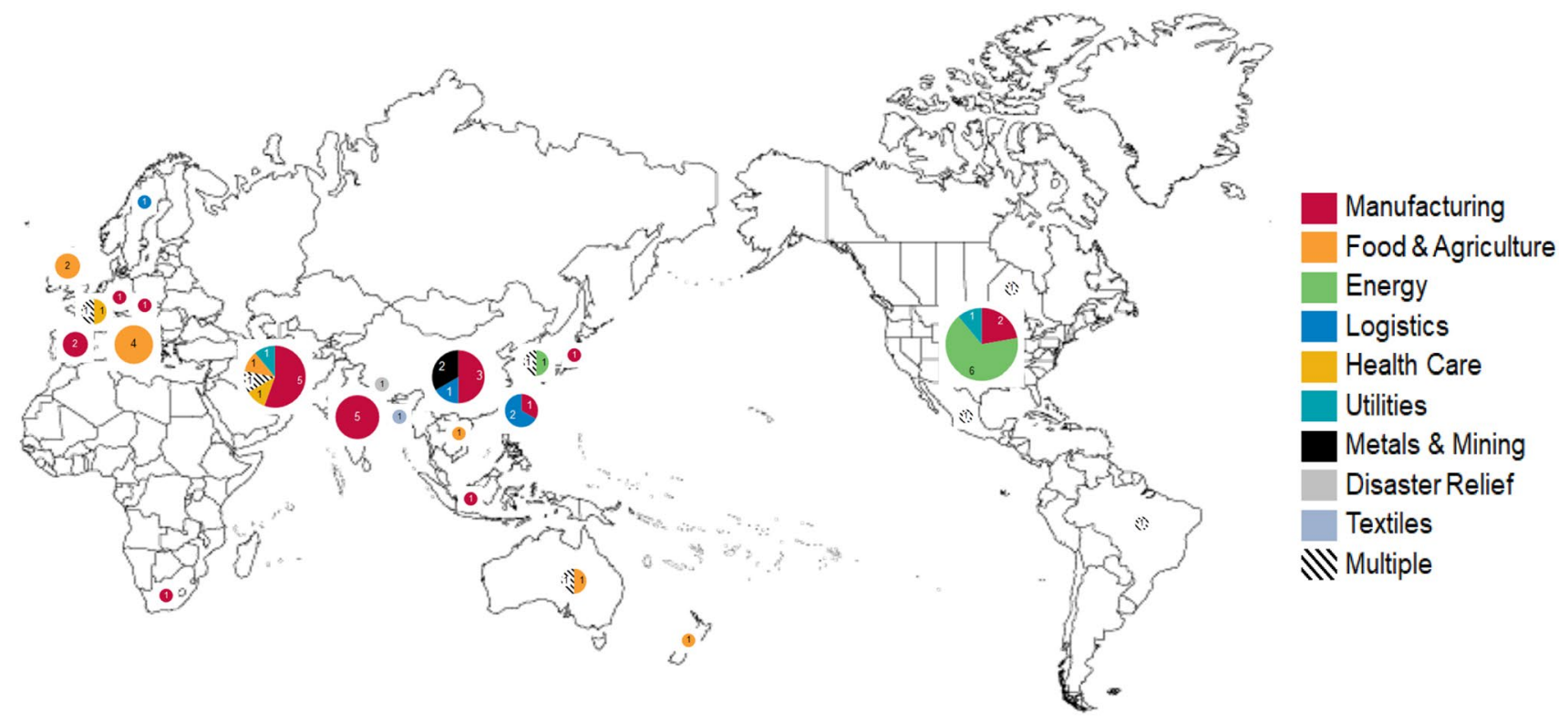

Fig. 10 Geo-economic representation of supply chain resilience papers by industry 
Table 4 Examples of sub-industries examined within each primary industry

\begin{tabular}{lll}
\hline $\begin{array}{l}\text { \# of Publi- } \\
\text { cations }\end{array}$ & Primary industry & Sub-industries \\
\hline 23 & Manufacturing & $\begin{array}{l}\text { Chemicals, electronics, electric \& combustion vehicles, glass, wood and paper, mining equipment, aero- } \\
\text { space, telecommunications }\end{array}$ \\
10 & Food \& Agriculture & $\begin{array}{l}\text { Citrus, kiwifruits, fisheries, dairy, tomato sauce, wine, spirit drinks, parmesan cheese, meat, rice } \\
\text { Liquified petroleum gas, transportation energy, motor fuel, biofuel, crude oil }\end{array}$ \\
7 & Energy & Port and maritime management, port-hinterland container transport, shipping, indigenous land, third party \\
2 & Logistics & Pharmaceuticals, blood \\
2 & Health Care & Solar PV, gas, water, electric \\
2 & Utilities & Rare earth metals, tantalum \\
1 & Metals \& Mining & N/A \\
1 & Disaster Relief & Apparel \\
6 & Textiles & N/A (papers examined more than one of the industries discussed above) \\
\hline
\end{tabular}

\section{Conclusions}

As the world becomes increasingly interconnected, supply chains grow in complexity. This global context provides a wealth of new opportunities for supply chain optimization and diversification, but also exposes supply chain networks to disruptions of increased complexity, uncertainty, and magnitude. Resilience is emerging as an important area within supply chain literature, but systematic studies on how it is defined and modeled are still rare. Our literature review shows the scale of growth in the field: this review augments a prior literature review of 47 papers published between 2007 and 2016 by adding 94 new papers published between 2017 and 2019. Such a significant growth in numbers does not change the challenges identified in our last review (Mersky et al. 2020). Still, this review has identified emerging issues and trends related to the use of $\mathrm{AI}$ and machine learning applications in the supply chain context, as well as a gap in the research capable of resilience analytics of systemic threats, such as the COVID-19 pandemic. Pandemics present a unique threat to supply chains as they are unpredictable, the impacts may be delayed, and the spread may be limitless with waves that can continue for months and even years.

We found a significant variability and diversity in supply chain resilience applications; the field would benefit significantly from a unifying modeling methodology and terminology. Consensus on definitions, metrics, and models for resilient supply chains does not exist, and a comprehensive, systems-based view is necessary for furthering the field of supply chain resilience. Current literature tends to focus on highly specific supply chain designs and niche markets and fails to consider the supply chain within the broader context of other networks, such as transportation and command and control (C2) networks. A movement towards common definitions, metrics, and models should be prioritized in order to create tangible tools for decision-makers.
Different supply chain applications may require different models and quantification approaches. For instance, a network representation may be extremely complex, as inputs and outputs may be linked in different ways, rely on different supply chains, and balance trade-offs and quantify risks with different weights. Moreover, interconnectedness of supply chains of individual products or serviced constituted supply chains may also be important to model and understand, as is seen with the case of personal protective equipment during the COVID-19 pandemic. A tiered approach proposed for resilience (Linkov et al. 2018) in which problem complexity dictates the increasing complexity of the modeling approach is recommended for supply chain resilience.

The systematic nature of our review has allowed us to identify main trends in the field. Since 2007 , a better understanding of resilience complexity in modeling is evidentover 50\% of all publications in 2017-2019 discuss all four components of resilience (plan, absorb, recover and adapt) while only $30 \%$ of the papers used all four components in the two years prior to this (i.e., 2015-2016). The modeling approaches also reflect a better understanding of resilience as a property of complex interconnected systems, as more papers use a graph representation of supply chain networks and utilize network science and other advanced tools (e.g., $\mathrm{AI}$ and machine learning). The supply chain is increasingly considered as a part of a multi-domain system of systems which includes transportation, communication, and $\mathrm{C} 2$ networks. There is also a shift from risk-based approaches where a threat is modeled as a defined scenario, often with uncertainty treated through Monte Carlo simulation, toward more complex threat representation through scenario analyses in case studies and threat-agnostic approaches.

An increasing volume of literature is focused on social aspects surrounding supply chain resilience, including collaboration with non-traditional supply chain stakeholders, which plays a role in increasing resilience during pandemic 
outbreaks. Collaboration between businesses, the public, and government has been spurred by public attention to environmental, social, human health, and governance-related performance and provides a means to address potential disruptions and risks along supply chains. Some publications analyze collaboration among businesses and between businesses and NGOs (Namdar et al. 2018; Revilla and Saenz 2017; Zeng 2017). Candelo et al. (2018) found evidence from previous authors that collaboration between NGOs and businesses is critical for decreasing vulnerability and meeting economic, social, and environmental objectives, which increases supply chain resilience (2018). This trend is leading from supply chain to value chain resilience (see Linkov et al. 2020 for discussions).

The highlighted trends are underscored by the COVID19 pandemic, which has demonstrated that the resilience of a single supply chain cannot be relied upon to prevent network failures and subsequent impact on the whole industry value chain. Advanced resilience analytics are necessary to ensure supply chain networks remain operational during global disruptions. Recent models of supply chain risk and recovery indicate that during the COVID-19 pandemic, the timing and sequence of bringing back online facilities at different echelons and nodes of the supply chain has the greatest impact on the supply chain performance (Ivanov 2020). Similarly, Li, H. et al. (2017a) show that information sharing between echelons improves supply chain resilience as disruptions in one supply chain are seen to propagate to others (2017). The idea of smart solutions and AI (Industry 4.0) is proposed to increase resilience. Although still unproven on a broader scale, Blockchain is proposed as a system for providing the visibility between supply chains tiers and echelons necessary to prevent supply chain network failure (Orcutt 2020); it is already used by some Chinese Aid organizations to increase trust and transparency (Joseph 2020). Several food and pharmaceutical supply chains have already implemented pilot studies on Blockchain to maintain agility and resilience during the COVID-19 pandemic (Gopie 2020). Smart contracts through Blockchain platforms can offer both proactive and reactive supply chain management (Dolgui et al. 2020). However, it is important to note that all these smart solutions may not necessarily add to system resilience (Marchese and Linkov 2017).

Further, the nature of global supply chains during the COVID-19 pandemic has minimized the impact of the geographic sources of epidemics, with threats to supply chains coming from the scale of the ripple effect (Ivanov 2020). Without a clear supply chain resilience model capable of tackling such a global threat, analysis of the COVID-19 pandemic will continue to be reactionary.

Pharmaceutical and medical supply chains have also failed during the COVID-19 pandemic in the wake of the implementation of lean global supply chains (Simchi-Levi and Simchi-Levi 2020). Similarly, at least $94 \%$ of Fortune 1000 companies have reported supply chain disruptions as a result of the COVID-19 pandemic (Ivanov 2020). As these companies recover, insights into the ripple effect and resilience analytics should be taken into account by managers to prevent such systemic failure during future disruptions. Understanding how the resilience of one supply chain relates to the resilience of another supply chain, and/or network such as transportation and $\mathrm{C} 2$, is essential for maintaining operations during systemic threats.

Based on our review, the following recommendations emerge to move the field of supply chain resilience analytics modeling forward:

1. (Re)consideration of the definition of supply chain resilience across all supply chain models and sectors is necessary to make resilience management more efficient. We recommend adoption of the standard four-stage definition of resilience provided by NAS - plan, absorb, recover, adapt;

2. Consideration of different types of disruptions within supply chain resilience models - especially assessing system recovery from unknown disruptions and systemic threats - is necessary to expand the scope that supply chain resilience management is able to quantify;

3. Consideration of the tiered approach to modeling, ranging from simple metrics to advanced network models, is necessary for understanding which quantification method to apply to the analytic need;

4. Consideration of the supply chain within the broader context of other networks that constitute value generation (e.g., command and control, cyber, transportation) is necessary for quantification of global network interactions and more robust supply chain resilience models that accurately portray trade-offs between efficiency and resilience to avoid cascading failures.

These considerations would enable supply chain managers to more efficiently factor, quantify and respond to disruptions and appropriately understand trade-offs in their decision-making. Only by addressing these research gaps will the field move toward a more comprehensive understanding of supply chain resilience, enabled by specific definitions and metrics that allow supply chain managers to quantitatively evaluate resilience strategies based on the severity of the expected or current disruption. Although pandemics may be a unique threat, modeling supply chain resilience should not be solely focused on the recovery stage; rather, equal weight must be given to the earlier stages as well. Trade-offs between being lean, efficient, and resilient should be visualized through resilience analytics and explicit modeling of the underlying networks (Ganin et al. 2017) and the value of 
resilience should be the guiding factor in deciding appropriate investments (Bostick et al. 2018).

Acknowledgements The authors are grateful to Dr. Avi Mersky for developing the review methodology and some elements of the classification scheme used in this paper. Comments and recommendations from Miriam Pollock, and Profs Jeff Keisler, Joe Sarkis, and Dmitry Ivanov helped to improve the paper quality and clarity. The views and opinions expressed in this paper are those of the individual authors and not those of the US Army or other sponsor organizations.

Conflict of interest The authors declare that they have no conflict of interest.

\section{References}

Akkermans H, Van Wassenhove LN (2018) Supply chain Tsunamis: research on low-probability, high-impact disruptions. J Supply Chain Manag 54(1):64-76. https://doi.org/10.1111/jscm.12162

Ali A, Mahfouz A, Arisha A (2017) Analysing supply chain resilience: Integrating the constructs in a concept mapping framework via a systematic literature review. Supply Chain Manag 22(1):16-39. https://doi.org/10.1108/SCM-06-2016-0197

Ali I, Nagalingam S, Gurd B (2018) A resilience model for cold chain logistics of perishable products. Int J Logist Manag 29(3):922941. https://doi.org/10.1108/JJLM-06-2017-0147

Bag S, Gupta S, Foropon C (2019) Examining the role of dynamic remanufacturing capability on supply chain resilience in circular economy. Manag Decis 57(4):863-885. https://doi.org/10.1108/ MD-07-2018-0724

Bak O (2018) Supply chain risk management research agenda: from a literature review to a call for future research directions. Bus Process Manag J 24(2):567-588. https://doi.org/10.1108/ BPMJ-02-2017-0021

Beheshtian A, Donaghy KP, Geddes RR, Rouhani OM (2017) Planning resilient motor-fuel supply chain. Int J Disaster Risk Reduct 24:312-325. https://doi.org/10.1016/j.ijdrr.2017.06.021

Beheshtian A, Donaghy KP, Richard Geddes R, Oliver Gao H (2018a) Climate-adaptive planning for the long-term resilience of transportation energy infrastructure. Transp Res Part E 113:99-122. https://doi.org/10.1016/j.tre.2018.02.009

Beheshtian A, Donaghy KP, Gao HO, Safaie S, Geddes R (2018b) Impacts and implications of climatic extremes for resilience planning of transportation energy: a case study of New York city. J Clean Prod 174:1299-1313. https://doi.org/10.1016/j.jclep ro.2017.11.039

Behzadi G, O'Sullivan MJ, Olsen TL, Zhang A (2018) Agribusiness supply chain risk management: a review of quantitative decision models. Omega 79:21-42. https://doi.org/10.1016/j.omega 2017.07.005

Bhattacharya A, Young P, Geraghty J, Byrne P (2013) Design of a resilient shock absorber for disrupted supply chain networks: a shock-dampening fortification framework for mitigating excursion events. Prod Plan Control 24(8-9):721-742. https://doi. org/10.1080/09537287.2012.666861

Bode C, Macdonald JR (2017) Stages of supply chain disruption response: direct, constraining, and mediating factors for impact mitigation: stages of supply chain disruption response. Decis Sci 48(5):836-874. https://doi.org/10.1111/deci.12245

Bogataj D, Bogataj M (2019) NPV approach to material requirements planning theory-a 50-year review of these research achievements. Int J Prod Res 57(15-16):5137-5153. https://doi. org/10.1080/00207543.2018.1524167

Bostick TP, Connelly EB, Lambert JH, Linkov I (2018) Resilience science, policy and investment for civil infrastructure. Reliab Eng Syst Saf. 175:19-23

Bottani E, Murino T, Schiavo M, Akkerman R (2019) Resilient food supply chain design: modelling framework and metaheuristic solution approach. Comput Ind Eng 135:177-198. https://doi. org/10.1016/j.cie.2019.05.011

Brusset X, Teller C (2017) Supply chain capabilities, risks, and resilience. Int J Prod Econ 184:59-68. https://doi.org/10.1016/j. ijpe.2016.09.008

Candelo E, Casalegno C, Civera C, Mosca F (2018) Turning farmers into business partners through value co-creation projects. Insights from the Coffee Supply Chain. Sustainability 10(4):1018. https:// doi.org/10.3390/su10041018

Cavalcante IM, Frazzon EM, Forcellini FA, Ivanov D (2019) A supervised machine learning approach to data-driven simulation of resilient supplier selection in digital manufacturing. Int J Inf Manag 49:86-97. https://doi.org/10.1016/j.ijinf omgt.2019.03.004

Chen H, Lam JSL, Liu N (2018) Strategic investment in enhancing port-hinterland container transportation network resilience: a network game theory approach. Transp Res Part B 111:83-112. https://doi.org/10.1016/j.trb.2018.03.004

Chen X, Xi Z, Jing P (2017) A unified framework for evaluating supply chain reliability and resilience. IEEE Trans Reliab 66(4):11441156. https://doi.org/10.1109/TR.2017.2737822

Cheng J-H, Lu K-L (2017) Enhancing effects of supply chain resilience: insights from trajectory and resource-based perspectives. Supply Chain Manag 22(4):329-340. https://doi.org/10.1108/ SCM-06-2016-0190

Chowdhury MMH, Quaddus M (2017) Supply chain resilience: conceptualization and scale development using dynamic capability theory. Int J Prod Econ 188:185-204. https://doi.org/10.1016/j. ijpe.2017.03.020

Christopher M, Holweg M (2017) Supply chain 2.0 revisited: a framework for managing volatility-induced risk in the supply chain. Int J Phys Distrib Logist Manag 47(1):2-17

Ciccullo F, Pero M, Caridi M, Gosling J, Purvis L (2018) Integrating the environmental and social sustainability pillars into the lean and agile supply chain management paradigms: a literature review and future research directions. J Clean Prod 172:23362350. https://doi.org/10.1016/j.jclepro.2017.11.176

Conz E, Denicolai S, Zucchella A (2017) The resilience strategies of SMEs in mature clusters. J Enterp Communities 11(1):186-210. https://doi.org/10.1108/JEC-02-2015-0015

Dalziell EP, McManus ST (2004) Resilience, vulnerability, and adaptive capacity: implications for system performance. In: Proceedings of the international forum for engineering decision making (6-8 Dec 2004), Stoos, Switzerland

Datta P (2017) Supply network resilience: a systematic literature review and future research. Int J Logist Manag 28(4):1387-1424. https ://doi.org/10.1108/IJLM-03-2016-0064

Dehghani E, Jabalameli MS, Jabbarzadeh A, Pishvaee MS (2018) Resilient solar photovoltaic supply chain network design under business-as-usual and hazard uncertainties. Comput Chem Eng 111:288-310. https://doi.org/10.1016/j.compchemen g.2018.01.013

Demont M, Rutsaert P (2017) Restructuring the Vietnamese Rice Sector: Towards Increasing Sustainability. Sustainability 9(2):325. https://doi.org/10.3390/su9020325

Deprá MC, dos Santos AM, Severo IA, Santos AB, Zepka LQ, JacobLopes E (2018) Microalgal biorefineries for bioenergy production: can we move from concept to industrial reality? BioEnergy Res 11(4):727-747. https://doi.org/10.1007/s12155-018-9934-Z 
Diabat A, Jabbarzadeh A, Khosrojerdi A (2019) A perishable product supply chain network design problem with reliability and disruption considerations. Int J Prod Econ 212:125-138. https://doi. org/10.1016/j.ijpe.2018.09.018

Dolgui A, Ivanov D, Sokolov B (2018) Ripple effect in the supply chain: an analysis and recent literature. Int J Prod Res 56(12):414-430. https://doi.org/10.1080/00207543.2017.1387680

Dolgui A, Ivanov D, Potryasaev S, Sokolov MI, Werner F (2020) Blockchain-oriented dynamic modelling of smart contract and execution in the supply chain. Int J Prod Res 58(7):2184-2199. https://doi.org/10.1080/00207543.2019.1627439

Dormady N, Roa-Henriquez A, Rose A (2019) Economic resilience of the firm: a production theory approach. Int J Prod Econ 208:446460. https://doi.org/10.1016/j.ijpe.2018.07.017

Dubey R, Altay N, Gunasekaran A, Blome C, Papadopoulos T, Childe SJ (2018) Supply chain agility, adaptability and alignment: Empirical evidence from the Indian auto components industry. International Journal of Operations \& Production Management 38(1):129-148. https://doi.org/10.1108/JJOPM-04-2016-0173

Durach CF, Machuca JAD (2018) A matter of perspective-the role of interpersonal relationships in supply chain risk management. Int J Oper Prod Manag 38(10):1866-1887. https://doi.org/10.1108/ IJOPM-03-2017-0157

Edwards J (2020) The Wildfire Crisis is Starting to Hurt Australian Companies. Bloomberg. Retrieved from: https://www.bloom berg.com/news/articles/2020-01-12/the-wildfire-crisis-is-start ing-to-hurt-australian-companies

Fassam L, Dani S (2017) A conceptual understanding of criminality and integrity challenges in food supply chains. Br Food J 119(1):67-83. https://doi.org/10.1108/BFJ-07-2016-0314

Fattahi M, Govindan K, Keyvanshokooh E (2017) Responsive and resilient supply chain network design under operational and disruption risks with delivery lead-time sensitive customers. Transp Res Part E 101:176-200. https://doi.org/10.1016/j. tre.2017.02.004

Gabler CB, Richey RG, Stewart GT (2017) Disaster resilience through public-private short-term collaboration. J Bus Logist 38(2):130144. https://doi.org/10.1111/jbl.12152

Galaitsi SE, Kiesler J, Trump B, Linkov I (2020, under review). The need to reconcile concepts that characterize systems under threat. https://arxiv.org/abs/1912.10457

Ganin A, Kitsak M, Marchese D, Keisler J, Seager T, Linkov I (2017) Resilience and efficiency in transportation networks. Sci Adv 3(12):e1701079. https://doi.org/10.1126/sciadv.1701079

Gao SY, Simchi-Levi D, Teo C-P, Yan Z (2019) Disruption risk mitigation in supply chains: the risk exposure index revisited. Oper Res 67(3):831-852. https://doi.org/10.1287/opre.2018.1776

Gaustad G, Krystofik M, Bustamante M, Badami K (2018) Circular economy strategies for mitigating critical material supply issues. Resour Conserv Recycl 135:24-33. https://doi.org/10.1016/j. resconrec.2017.08.002

Ghavamifar A, Makui A, Taleizadeh AA (2018) Designing a resilient competitive supply chain network under disruption risks: a realworld application. Transp Res Part E 115:87-109. https://doi. org/10.1016/j.tre.2018.04.014

Gligor D, Gligor N, Holcomb M, Bozkurt S (2019) Distinguishing between the concepts of supply chain agility and resilience: a multidisciplinary literature review. Int J Logist Manag 30(2):467-487. https://doi.org/10.1108/IJLM-10-2017-0259

Gopie N (2020) Blockchain's role in COVID-19 response and recovery. Blockchain Pulse: IBM Blockchain Blog, IBM. https://www.ibm. com/blogs/blockchain/2020/04/blockchains-role-in-covid-19response-and-recovery/

Graça P, Camarinha-Matos LM (2017) Performance indicators for collaborative business ecosystems-literature review and trends. Technol Forecast Soc Chang 116:237-255. https://doi. org/10.1016/j.techfore.2016.10.012

Hosseini S, Ivanov D, Dolgui A (2019a) Review of quantitative methods for supply chain resilience analysis. Transp Res Part E 125:285-307. https://doi.org/10.1016/j.tre.2019.03.001

Hosseini S, Morshedlou N, Ivanov D, Sarder MD, Barker K, Khaled AA (2019b) Resilient supplier selection and optimal order allocation under disruption risks. Int J Prod Econ 213:124-137. https ://doi.org/10.1016/j.ijpe.2019.03.018

Ivanov D (2017) Simulation-based ripple effect modelling in the supply chain. Int J Prod Res 55(7):2083-2101. https://doi. org/10.1080/00207543.2016.1275873

Ivanov D (2018) Revealing interfaces of supply chain resilience and sustainability: a simulation study. Int J Prod Res 56(10):35073523. https://doi.org/10.1080/00207543.2017.1343507

Ivanov D (2019) Disruption tails and revival policies: a simulation analysis of supply chain design and production-ordering systems in the recovery and post-disruption periods. Comput Ind Eng 127:558-570. https://doi.org/10.1016/j.cie.2018.10.043

Ivanov D (2020) Predicting the impacts of epidemic outbreaks on global supply chains: a simulation-based analysis on the coronavirus outbreak (COVID-19/SARS-CoV-2) case. Transp Res Part E. https://doi.org/10.1016/j.tre.2020.101922

Ivanov D, Das A, Choi T-M (2018) New flexibility drivers for manufacturing, supply chain and service operations. Int $\mathbf{J}$ Prod Res 56(10):3359-3368. https://doi.org/10.1080/00207 543.2018 .1457813

Ivanov D, Dolgui A (2020) Viability of intertwined supply networks: extending the supply chain resilience angles towards survivability. A position paper motivated by COVID-19 outbreak. Int J Prod Res. https://doi.org/10.1080/00207543.2020.1750727

Ivanov D, Dolgui A, Sokolov B, Ivanova M (2017) Literature review on disruption recovery in the supply chain. Int $\mathbf{J}$ Prod Res 55(20):6158-6174. https://doi.org/10.1080/00207 543.2017.1330572

Jabbarzadeh A, Haughton M, Khosrojerdi A (2018) Closed-loop supply chain network design under disruption risks: a robust approach with real world application. Comput Ind Eng 116:178-191. https ://doi.org/10.1016/j.cie.2017.12.025

Joseph G (2020) Can blockchain save the supply chain from COVID19? NASDAQ. https://www.nasdaq.com/articles/can-blockchain -save-the-supply-chain-from-covid-19-2020-04-21

Kamalahmadi M, Parast MM (2017) An assessment of supply chain disruption mitigation strategies. Int J Prod Econ 184:210-230. https://doi.org/10.1016/j.ijpe.2016.12.011

Khalili SM, Jolai F, Torabi SA (2017) Integrated production-distribution planning in two-echelon systems: a resilience view. Int J Prod Res 55(4):1040-1064. https://doi.org/10.1080/00207 543.2016.1213446

Khalili JS, Zhu H, Mak NSA, Yan Y, Zhu Y (2020) Novel coronavirus treatment with ribavirin: groundwork for an evaluation concerning COVID-19. J Med Virol. https://doi.org/10.1002/jmv.25798

Khaslavskaya A, Roso V (2019) Outcome-driven supply chain perspectives on dry ports. Sustainability 11(5):1492. https://doi. org/10.3390/su11051492

Khemiri R, Elbedoui-Maktouf K, Grabot B, Zouari B (2017) A fuzzy multi-criteria decision-making approach for managing performance and risk in integrated procurement-production planning. Int J Prod Res 55(18):5305-5329. https://doi.org/10.1080/00207 543.2017 .1308575

Kurılmaz O, Erol S (2017) A proactive approach to supply chain risk management: shifting orders among suppliers to mitigate the supply side risks. J Purch Supply Manag 23(1):54-65. https://doi. org/10.1016/j.pursup.2016.04.002

Kong Y, Zhang M, Ye D (2017) A belief propagation-based method for task allocation in open and dynamic cloud environments. 
Knowl Based Syst 115:123-132. https://doi.org/10.1016/j.knosy s.2016.10.016

Kristianto Y, Gunasekaran A, Helo P (2017) Building the "Triple R" in global manufacturing. Int J Prod Econ 183:607-619. https:// doi.org/10.1016/j.ijpe.2015.12.011

Kurniawan R, Zailani SH, Iranmanesh M, Rajagopal P (2017) The effects of vulnerability mitigation strategies on supply chain effectiveness: risk culture as moderator. Supply Chain Manag 22(1):1-15. https://doi.org/10.1108/SCM-12-2015-0482

Kwak D-W, Seo Y-J, Mason R (2018) Investigating the relationship between supply chain innovation, risk management capabilities and competitive advantage in global supply chains. Int $\mathbf{J}$ Oper Prod Manag 38(1):2-21. https://doi.org/10.1108/IJOPM -06-2015-0390

Kwesi-Buor J, Menachof DA, Talas R (2019) Scenario analysis and disaster preparedness for port and maritime logistics risk management. Accid Anal Prev 123:433-447. https://doi. org/10.1016/j.aap.2016.07.013

Lee S (2017) A fuzzy multi-objective programming approach for determination of resilient supply portfolio under supply failure risks. J Purch Supply Manag 23(3):211-220. https://doi. org/10.1016/j.pursup.2017.01.003

Li H, Pedrielli G, Lee LH, Chew EP (2017a) Enhancement of supply chain resilience through inter-echelon information sharing. Flex Serv Manuf J 29(2):260-285. https://doi.org/10.1007/ s10696-016-9249-3

Li R, Dong Q, Jin C, Kang R (2017b) A new resilience measure for supply chain networks. Sustainability 9(1):144. https://doi. org/10.3390/su9010144

Lim-Camacho L, Plagányi ÉE, Crimp S, Hodgkinson JH, Hobday AJ, Howden SM, Loechel B (2017) Complex resource supply chains display higher resilience to simulated climate shocks. Glob Environ Chang 46:126-138. https://doi.org/10.1016/j. gloenvcha.2017.08.011

Linkov I, Carluccio S, Pritchard O, Bhreasail AN, Galaitsi S, Sarkis, J, Keisler J (2020, under review). Value chain resilience. Manag Res Rev

Linnenluecke MK (2017) Resilience in business and management research: a review of influential publications and a research agenda: resilience in business and management research. Int J Manag Rev 19(1):4-30. https://doi.org/10.1111/ijmr.12076

Liu C-L, Lee M-Y (2018) Integration, supply chain resilience, and service performance in third-party logistics providers. Int J Logist Manag 29(1):5-21. https://doi.org/10.1108/ IJLM-11-2016-0283

Liu C-L, Shang K-C, Lirn T-C, Lai K-H, Lun YHV (2018) Supply chain resilience, firm performance, and management policies in the liner shipping industry. Transp Res Part A 110:202-219. https ://doi.org/10.1016/j.tra.2017.02.004

Lohr S (2011) Stress test for the global supply Chain. The New York Times. Retrieved from: https://www.nytimes.com/2011/03/20/ business/20supply.html

Lotfi M, Saghiri S (2018) Disentangling resilience, agility and leanness: conceptual development and empirical analysis. J Manuf Technol Manag 29(1):168-197. https://doi.org/10.1108/ JMTM-01-2017-0014

Maheshwari P, Singla S, Shastri Y (2017) Resiliency optimization of biomass to biofuel supply chain incorporating regional biomass pre-processing depots. Biomass Bioenergy 97:116-131. https:// doi.org/10.1016/j.biombioe.2016.12.015

Mancheri NA, Sprecher B, Bailey G, Ge J, Tukker A (2019) Effect of Chinese policies on rare earth supply chain resilience. Resour Conserv Recycl 142:101-112. https://doi.org/10.1016/j.resco nrec.2018.11.017

Mancheri NA, Sprecher B, Deetman S, Young SB, Bleischwitz R, Dong L, Kleijn R, Tukker A (2018) Resilience in the tantalum supply chain. Resour Conserv Recycl 129:56-69. https://doi. org/10.1016/j.resconrec.2017.10.018

Mancini MC, Arfini F (2018) Short supply chains and Protected Designations of Origin: The case of Parmigiano Reggiano (Italy). Ager. Revista de Estudios Sobre Despoblación y Desarrollo Rural 25:43-64. https://doi.org/10.4422/ager.2018.11

Marchese D, Linkov I (2017) Can you be smart and resilient at the same time? Environ Sci Technol 51:5867-5868. https://doi. org/10.1021/acs.est.7b01912

Margolis JT, Sullivan KM, Mason SJ, Magagnotti M (2018) A multi-objective optimization model for designing resilient supply chain networks. Int J Prod Econ 204:174-185. https://doi. org/10.1016/j.ijpe.2018.06.008

Mersky, A., Golan, M., Linkov, I. (2020). Quantitative Modeling of Supply Chain Resilience: a Literature Review. Cybersecurity and Resilience in the Arctic. IOS Press.

Mizgier KJ (2017) Global sensitivity analysis and aggregation of risk in multi-product supply chain networks. Int J Prod Res 55(1):130 144. https://doi.org/10.1080/00207543.2016.1198504

Moghaddam M, Nof SY (2017) The collaborative factory of the future. Int J Comput Integr Manuf 30(1):23-43

Mohammed A, Harris I, Soroka A, Nujoom R (2019) A hybrid MCDMfuzzy multi-objective programming approach for a G-resilient supply chain network design. Comput Ind Eng 127:297-312. https://doi.org/10.1016/j.cie.2018.09.052

Morshedlou N, González AD, Barker K (2018) Work crew routing problem for infrastructure network restoration. Transp Res Part B 118:66-89. https://doi.org/10.1016/j.trb.2018.10.001

Namany S, Al-Ansari T, Govindan R (2019) Sustainable energy, water and food nexus systems: a focused review of decision-making tools for efficient resource management and governance. J Clean Prod 225:610-626. https://doi.org/10.1016/j.jclepro.2019.03.304

Namdar J, Li X, Sawhney R, Pradhan N (2018) Supply chain resilience for single and multiple sourcing in the presence of disruption risks. Int J Prod Res 56(6):2339-2360. https://doi. org/10.1080/00207543.2017.1370149

National Geographic (2011) Rare Video: Japan Tsunami. Retrieved from: https://www.youtube.com/watch? $\mathrm{v}=\mathrm{oWzdgBNfhQU}$

Ni N, Howell BJ, Sharkey TC (2018) Modeling the impact of unmet demand in supply chain resiliency planning. Omega 81:1-16. https://doi.org/10.1016/j.omega.2017.08.019

Oliveira JB, Jin M, Lima RS, Kobza JE, Montevechi JAB (2019) The role of simulation and optimization methods in supply chain risk management: performance and review standpoints. Simul Model Pract Theory 92:17-44. https://doi.org/10.1016/j.simpa t.2018.11.007

Orcutt M (2020) The pandemic has messed up global supply chains: Blockchains could help.MIT Technology Review. https://www. technologyreview.com/2020/04/07/998602/blockchains-covid 19-supply-chain-wef/

Otto C, Willner SN, Wenz L, Frieler K, Levermann A (2017) Modeling loss-propagation in the global supply network: the dynamic agent-based model acclimate. J Econ Dyn Control 83:232-269. https://doi.org/10.1016/j.jedc.2017.08.001

Pinho de Lima FR, Da Silva AL, Godinho Filho M, Dias EM (2018) Systematic review: resilience enablers to combat counterfeit medicines. Supply Chain Manag 23(2):117-135. https://doi. org/10.1108/SCM-04-2017-0155

Panetto H, Iung B, Ivanov D, Weichhart G, Wang X (2019) Challenges for the cyber-physical manufacturing enterprises of the future. Annu Rev Control 47:200-213. https://doi.org/10.1016/j.arcon trol.2019.02.002

Papadopoulos T, Gunasekaran A, Dubey R, Altay N, Childe SJ, Fosso-Wamba S (2017) The role of Big Data in explaining disaster resilience in supply chains for sustainability. J Clean Prod 142:1108-1118. https://doi.org/10.1016/j.jclepro.2016.03.059 
Paul SK, Asian S, Goh M, Torabi SA (2019) Managing sudden transportation disruptions in supply chains under delivery delay and quantity loss. Ann Oper Res 273(1-2):783-814. https://doi. org/10.1007/s10479-017-2684-Z

Patel A, D'Alessandro MM, Ireland KJ, Burel G, Wencil EB, Rasmussen SA (2017) Personal protective equipment supply chain: lessons learned from recent public health emergency responses. Health Secur 15(3):244-252. https://doi.org/10.1089/ hs.2016.0129

Pavlov A, Ivanov D, Dolgui A, Sokolov B (2018) Hybrid fuzzy-probabilistic approach to supply chain resilience assessment. IEEE Trans Eng Manag 65(2):303-315. https://doi.org/10.1109/ TEM.2017.2773574

Ponomarov SY, Holcomb MC (2009) Understanding the concept of supply chain resilience. Int J Logist Manag 20(1):124-143

Pourhejazy P, Kwon O, Chang Y-T, Park H (2017) Evaluating resiliency of supply chain network: a data envelopment analysis approach. Sustainability 9(2):255. https://doi.org/10.3390/su902 0255

Prosperi P, Kirwan J, Maye D, Bartolini F, Vergamini D, Brunori G (2019) Adaptation strategies of small-scale fisheries within changing market and regulatory conditions in the EU. Mar Policy 100:316-323. https://doi.org/10.1016/j.marpol.2018.12.006

Rajagopal V, Prasanna Venkatesan S, Goh M (2017) Decision-making models for supply chain risk mitigation: a review. Comput Ind Eng 113:646-682. https://doi.org/10.1016/j.cie.2017.09.043

Rajesh R (2017) Technological capabilities and supply chain resilience of firms: a relational analysis using Total Interpretive Structural Modeling (TISM). Technol Forecast Soc Chang 118:161-169. https://doi.org/10.1016/j.techfore.2017.02.017

Rajesh R (2018) Measuring the barriers to resilience in manufacturing supply chains using Grey Clustering and VIKOR approaches. Measurement 126:259-273. https://doi.org/10.1016/j.measu rement.2018.05.043

Rajesh R, Ravi V (2017) Analyzing drivers of risks in electronic supply chains: a grey-DEMATEL approach. Int J Adv Manuf Technol 92(1-4):1127-1145. https://doi.org/10.1007/s00170-017-0118-3

Ramezankhani MJ, Torabi SA, Vahidi F (2018) Supply chain performance measurement and evaluation: a mixed sustainability and resilience approach. Comput Ind Eng 126:531-548. https://doi. org/10.1016/j.cie.2018.09.054

Revilla E, Saenz MJ (2017) The impact of risk management on the frequency of supply chain disruptions: a configurational approach. Int J Oper Prod Manag 37(5):557-576. https://doi.org/10.1108/ IJOPM-03-2016-0129

Rezapour S, Farahani RZ, Pourakbar M (2017) Resilient supply chain network design under competition: a case study. Eur J Oper Res 259(3):1017-1035. https://doi.org/10.1016/j.ejor.2016.11.041

Ribeiro JP, Barbosa-Povoa A (2018) Supply chain resilience: definitions and quantitative modelling approaches-a literature review. Comput Ind Eng 115:109-122. https://doi.org/10.1016/j. cie.2017.11.006

Rose A, Wei D, Paul D (2018) Economic consequences of and resilience to a disruption of petroleum trade: the role of seaports in U.S. energy security. Energy Policy 115:584-615. https://doi. org/10.1016/j.enpol.2017.12.052

Rowen NJ, Laffey JG (2020) Challenges and solutions for addressing critical shortage of supply chain for personal and protective equipment (PPE) arising from Coronavirus disease (COVID19) pandemic - case study from the Republic of Ireland. Sci Total Environ. https://doi.org/10.1016/j.scitotenv.2020.138532

Ruiz-Benitez R, López C, Real JC (2017) Environmental benefits of lean, green and resilient supply chain management: the case of the aerospace sector. J Clean Prod 167:850-862. https://doi. org/10.1016/j.jclepro.2017.07.201
Ruiz-Benítez R, López C, Real JC (2018) The lean and resilient management of the supply chain and its impact on performance. Int J Prod Econ 203:190-202. https://doi.org/10.1016/j. ijpe.2018.06.009

Sabouhi F, Pishvaee MS, Jabalameli MS (2018) Resilient supply chain design under operational and disruption risks considering quantity discount: a case study of pharmaceutical supply chain. Comput Ind Eng 126:657-672

Sahu AK, Datta S, Mahapatra SS (2017) Evaluation of performance index in resilient supply chain: a fuzzy-based approach. Benchmarking 24(1):118-142. https://doi.org/10.1108/ BIJ-07-2015-0068

Sauer PC, Seuring S (2019) Extending the reach of multi-tier sustainable supply chain management-insights from mineral supply chains. Int J Prod Econ 217:31-43. https://doi.org/10.1016/j. ijpe.2018.05.030

Scheibe KP, Blackhurst J (2018) Supply chain disruption propagation: a systemic risk and normal accident theory perspective. Int J Prod Res 56(1-2):43-59. https://doi.org/10.1080/00207 543.2017.1355123

Shishodia A, Verma P, Dixit V (2019) Supplier evaluation for resilient project driven supply chain. Comput Ind Eng 129:465-478. https ://doi.org/10.1016/j.cie.2019.02.006

Sheffi Y (2015) A classification of catastrophes. The power of resilience. How the best companies manage the unexpected. The MIT Press, Cambridge

Sheffi Y, Rice JB Jr (2005) A supply chain view of the resilient enterprise. MIT Sloan Manag Rev 47(1):41-48

Simchi-Levi D, Simchi-Levi E (2020) We need a stress test for critical supply chains. Harvard Business Review. https://hbr-org.cdn. ampproject.org/c/s/hbr.org/amp/2020/04/we-need-a-stress-testfor-critical-supply-chains

Smart P, Hemel S, Lettice F, Adams R, Evans S (2017) Pre-paradigmatic status of industrial sustainability: a systematic review. Int J Oper Prod Manag 37(10):1425-1450. https://doi.org/10.1108/ IJOPM-02-2016-0058

Stone J, Rahimifard S (2018) Resilience in agri-food supply chains: a critical analysis of the literature and synthesis of a novel framework. Supply Chain Manag 23(3):207-238. https://doi. org/10.1108/SCM-06-2017-0201

Treiblmaier H (2018) Optimal levels of (de)centralization for resilient supply chains. Int J Logist Manag 29(1):435-455. https://doi. org/10.1108/IJLM-01-2017-0013

Tseng M-L, Lim M, Wu K-J, Zhou L, Bui DTD (2018) A novel approach for enhancing green supply chain management using converged interval-valued triangular fuzzy numbers-grey relation analysis. Resour Conserv Recycl 128:122-133

Tukamuhabwa B, Stevenson M, Busby J (2017) Supply chain resilience in a developing country context: a case study on the interconnectedness of threats, strategies and outcomes. Supply Chain Manag 22(6):486-505. https://doi.org/10.1108/SCM-02-2017-0059

United Nations (2019) World Economic Situation and Prospects. United Nations. Retrieved from: https://www.un.org/developmen t/desa/dpad/wp-content/uploads/sites/45/WESP2019_BOOKANNEX-en.pdf

Valipour Parkouhi S, Safaei Ghadikolaei A (2017) A resilience approach for supplier selection: Using Fuzzy Analytic Network Process and grey VIKOR techniques. J Clean Prod 161:431-451. https://doi.org/10.1016/j.jclepro.2017.04.175

Valipour Parkouhi S, Safaei Ghadikolaei A, Fallah Lajimi H (2019) Resilient supplier selection and segmentation in grey environment. J Clean Prod 207:1123-1137. https://doi.org/10.1016/j. jclepro.2018.10.007

Viljoen NM, Joubert JW (2018) The road most travelled: the impact of urban road infrastructure on supply chain network vulnerability. 
Netw Spat Econ 18(1):85-113. https://doi.org/10.1007/s1106 7-017-9370-1

Wang J, Dou R, Muddada RR, Zhang W (2018) Management of a holistic supply chain network for proactive resilience: Theory and case study. Comput Ind Eng 125:668-677. https://doi. org/10.1016/j.cie.2017.12.021

Wang T-K, Zhang Q, Chong H-Y, Wang X (2017) Integrated supplier selection framework in a resilient construction supply chain: an approach via analytic hierarchy process (AHP) and grey relational analysis (GRA). Sustainability 9(2):289. https://doi. org/10.3390/su9020289

World Health Organization (2020) Shortage of personal protective equipment endangering health workers worldwide. WHO, Geneva. https://www.who.int/news-room/detail/03-03-2020shortage-of-personal-protective-equipment-endangering-healt h-workers-worldwide

World Nuclear Association (2018) Fukushima Daiichi Accident. Retrieved from: https://www.world-nuclear.org/information-libra ry/safety-and-security/safety-of-plants/fukushima-accident.aspx

Yang Y, Pan S, Ballot E (2017) Mitigating supply chain disruptions through interconnected logistics services in the Physical Internet. Int J Prod Res 55(14):3970-3983. https://doi.org/10.1080/00207 543.2016 .1223379

Yavari M, Zaker H (2019) An integrated two-layer network model for designing a resilient green-closed loop supply chain of perishable products under disruption. J Clean Prod 230:198-218. https://doi. org/10.1016/j.jclepro.2019.04.130

Yoon J, Talluri S, Yildiz H, Ho W (2018) Models for supplier selection and risk mitigation: a holistic approach. Int J Prod Res 56(10):3636-3661. https://doi.org/10.1080/00207 543.2017 .1403056

Zahiri B, Zhuang J, Mohammadi M (2017) Toward an integrated sustainable-resilient supply chain: a pharmaceutical case study. Transport Res Part E 103:109-142. https://doi.org/10.1016/j. tre.2017.04.009

Zavitsas K, Zis T, Bell MGH (2018) The impact of flexible environmental policy on maritime supply chain resilience. Transp Policy 72:116-128. https://doi.org/10.1016/j.tranpol.2018.09.020

Zeng B, Yen BP-C (2017) Rethinking the role of partnerships in global supply chains: a risk-based perspective. Int J Prod Econ 185:5262. https://doi.org/10.1016/j.ijpe.2016.12.004

Zhalechian M, Torabi SA, Mohammadi M (2018) Hub-and-spoke network design under operational and disruption risks. Transport Res Part E 109:20-43. https://doi.org/10.1016/j.tre.2017.11.001

Zhao S, You F (2019) Resilient supply chain design and operations with decision-dependent uncertainty using a data-driven robust optimization approach. AIChE J 65(3):1006-1021. https://doi. org/10.1002/aic.16513 